EVALUATION OF VIROLOGIC MONITORING FREQUENCIES ON RESPONSES TO ANTIRETROVIRAL THERAPY IN HIV-1 INFECTED PATIENTS

by

TOLYBERT MUNODAWAFA ZHOU

submitted in accordance with the requirements

for the degree of

MASTER OF PUBLIC HEALTH

at the

University of South Africa

Supervisor: PROF MC MATLAKALA

NOVEMBER 2017 


\section{DECLARATION}

Name: Tolybert Munodawafa Zhou

Student number: 50778587

Degree: MASTER OF PUBLIC HEALTH

Exact wording of the title of the dissertation or thesis as appearing on the copies submitted for examination:

EVALUATION OF VIROLOGIC MONITORING FREQUENCIES ON RESPONSES TO ANTIRETROVIRAL THERAPY IN HIV-1 INFECTED PATIENTS

I declare that the above dissertation/thesis is my own work and that all the sources that I have used or quoted have been indicated and acknowledged by means of complete references.

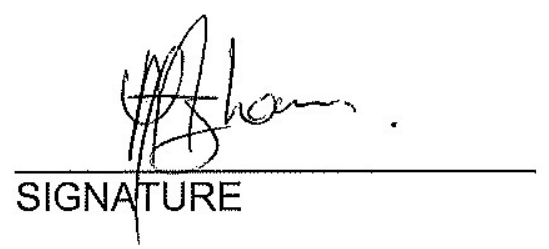

$$
\frac{13 / 10 / 2017}{\text { DATE }}
$$




\title{
EVALUATION OF VIROLOGIC MONITORING FREQUENCIES ON RESPONSES TO ANTIRETROVIRAL THERAPY IN HIV-1 INFECTED PATIENTS
}

\author{
Student number: \\ Student name: \\ 50778587 \\ Degree: \\ Department: \\ Tolybert Munodawafa Zhou \\ Master of Public Health \\ Health Studies \\ Supervisor: \\ Prof MC Matlakala
}

\section{ABSTRACT}

The purpose of this study was to assess the impact of virologic monitoring frequencies on treatment failure, adherence to therapy, and the emergence of drug resistance in HIV-1 infected patients. A quantitative, meta-analysis was conducted to investigate the virologic outcomes of infrequent and frequent Viral Load (VL) testing among patient on combination antiretroviral therapy (cART). Data was collected through a self-designed data collection form. Two comparison groups emerged being guided by the VL monitoring frequency. In group I, the health outcomes were compared for ( $\geq 3$ VLs per year) versus ( $\leq 2$ VLs per year) and (2 VLs per year) versus ( $\leq 1$ VLs per year) for group II. Data were analysed using the Cochrane's statistical software, RevMan v5.3. The findings support (2 VLs per year) as the optimal VL monitoring strategy for stable and virologically suppressed patients and there is nothing to be gained by ( $\geq 3$ VLs per year).

\section{Key concepts}

Anti-retroviral (ARV) drugs; Viral load (VL); Virologic monitoring frequencies; Responses to antiretroviral therapy; HIV-1 infected patients; Evaluation. 


\section{ACKNOWLEDGEMENTS}

I want to thank the following persons for support and contributions to this dissertation:

- I thank God for His providence; He gave me courage and confidence to study.

- $\quad$ My wife, Mrs Samkeliso Zhou, for her availability, unconditional support and understanding at all times. Her words of encouragement helped me to keep up the study momentum, even way past midnight.

- Grateful thanks goes to my supervisor, Prof Mokgadi Matlakala, for her guidance, support and encouragement throughout. She attended to my documents several times and was very patient.

- $\quad$ The UNISA librarian, Velaphi Kheswa, for the assistance on Refworks.

- $\quad$ The UNISA Information Search Librarians, for the literature search.

- I am grateful to Ellen C Caniglia and R. David Parker for providing me with the documents for research support.

- I am particularly grateful for the support provided by the Cochrane organization for availing the Review Manager 5.3 (RevMan 5) that I used for data analysis.

- I am grateful to Helena VonVille from the University Of Texas School Of Public Health Library for creating and availing the "PRIMARY Excel Workbook for Systematic Reviews" used to guide the search process.

- $\quad$ My parents Mr and Mrs Zhou for their continued support.

- My sincere gratitude to my colleague Obert Kachuwaire who always gave me advisory encouragement to continue.

- $\quad$ My employer Mr. Oremeng Motshegare for his support 


\section{Dedication}

This study is dedicated to the following people who inspired me to pursue my life and studies with passion and determination.

- My two loving children, Ian and Eric Zhou, because of whom I have developed hope. They gave me unconditional love, support and prayed for this research to be a success. I long to be a good role model, and hope they will grow to be determined and successful adults.

- My Wife, Mrs. Samkeliso Zhou for her support, and I hope to motivate and inspire her to continue excelling in her studies.

- My Brother Robin Zhou who once shared with me a quote by Henry Wadsworth Longfellow "The heights by great men reached and kept were not attained by sudden flight, but they, while their companions slept, were toiling upward in the night". 


\section{Table of Contents}

\section{CHAPTER 1 \\ ORIENTATION TO THE STUDY}

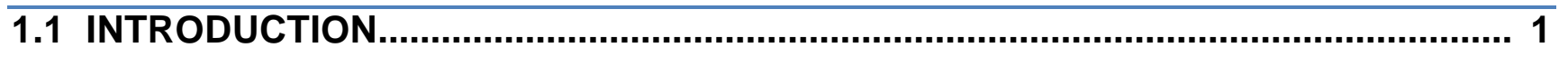

1.2 BACKGROUND TO THE RESEARCH PROBLEM .................................................. 2

1.3 STATEMENT OF THE RESEARCH PROBLEM ................................................ 3

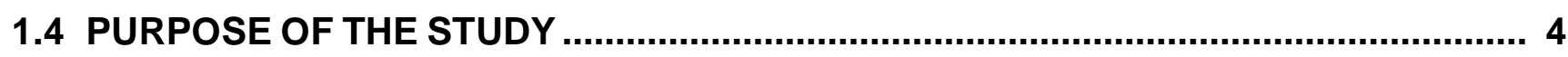

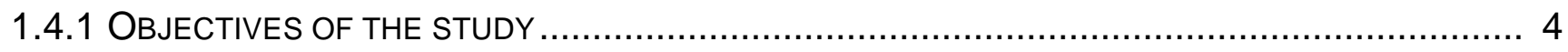

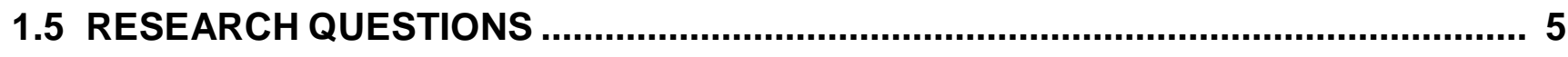

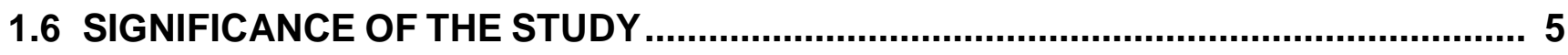

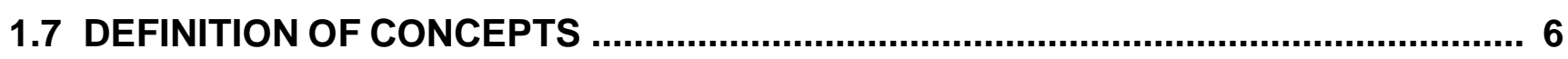

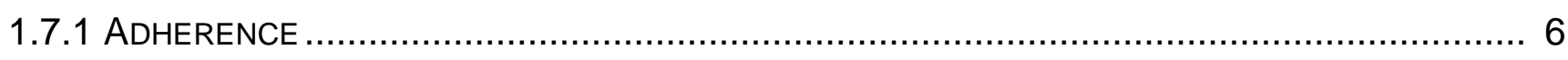

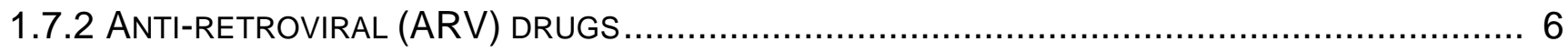

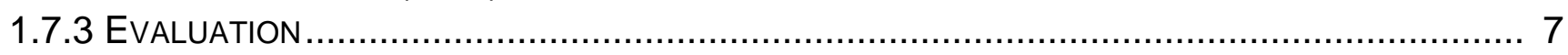

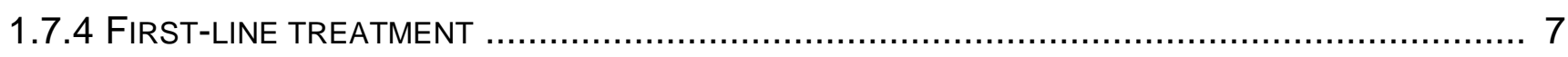

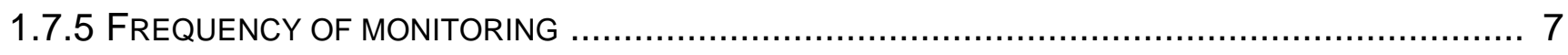

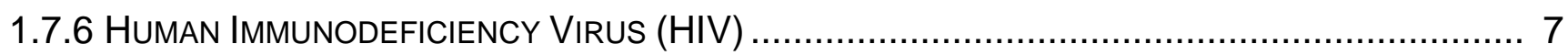

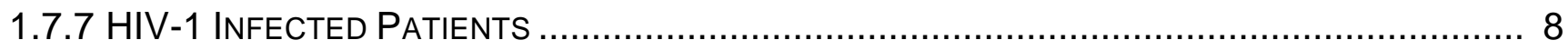

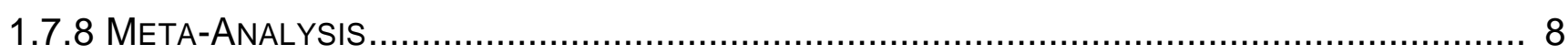

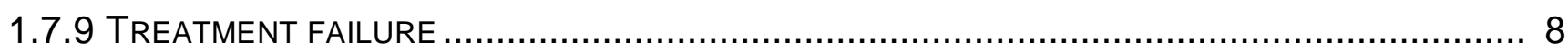

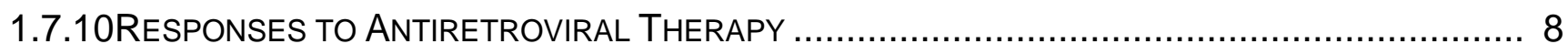

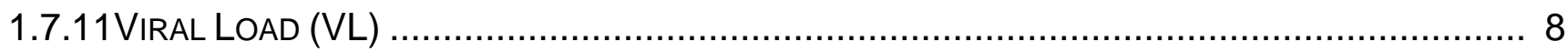

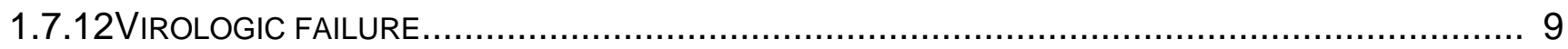

1.7.13VIROLOGIC MONITORING FREQUENCIES ............................................................. 9

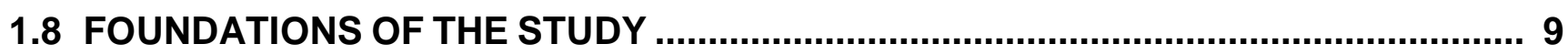

1.9 INTRODUCTION TO RESEARCH DESIGN AND METHODOLOGY........................... 10

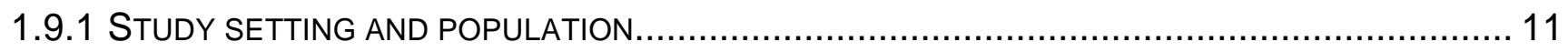

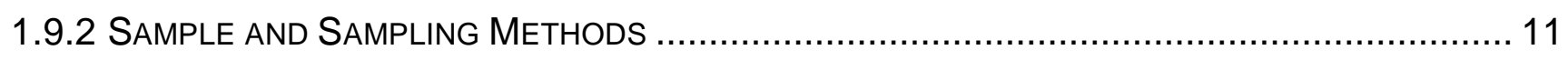

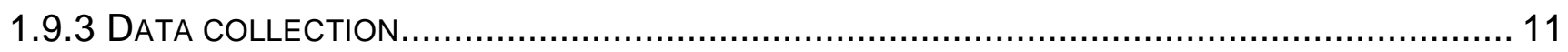

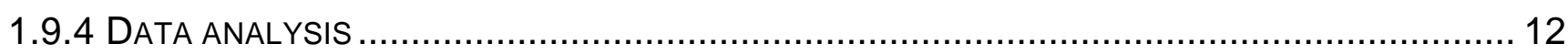

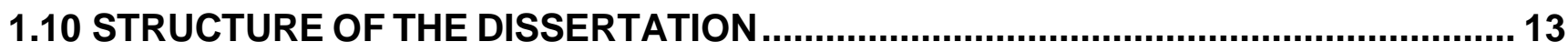

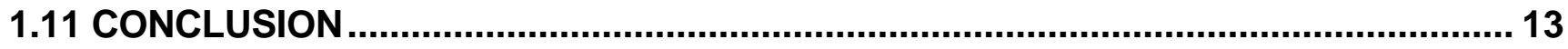


CHAPTER 2

\section{LITERATURE REVIEW}

2.1 INTRODUCTION............................................................................................... 14

2.2 MONITORING FREQUENCY ........................................................................... 14

2.3 VIROLOGIC FAILURE ......................................................................................... 15

2.4 ADHERENCE ................................................................................................. 16

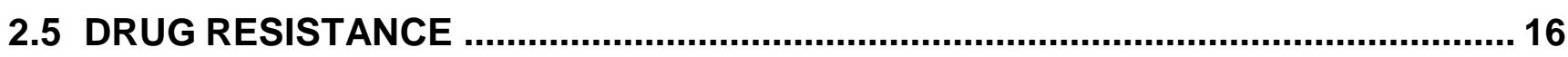

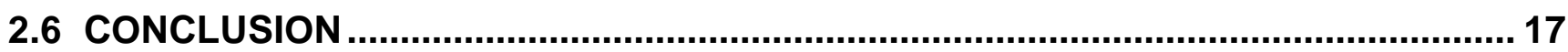

CHAPTER 3

RESEARCH DESIGN AND METHODOLOGY

3.1 INTRODUCTION.............................................................................................. 18

3.2 ELIGIBILITY CRITERIA .................................................................................... 18

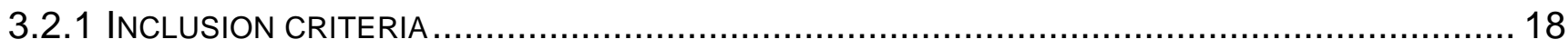

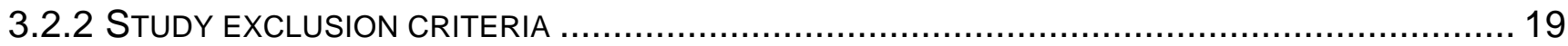

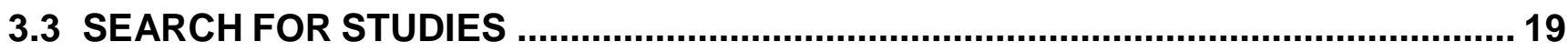

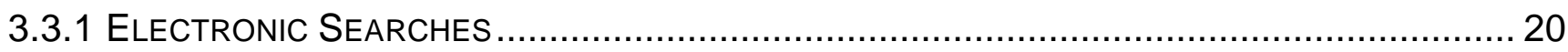

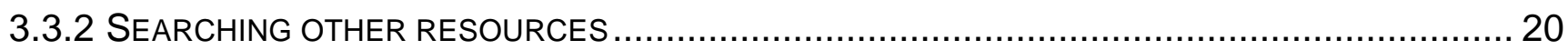

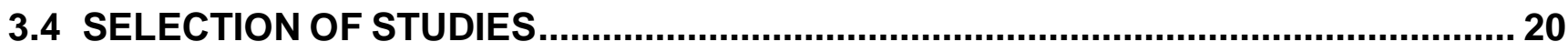

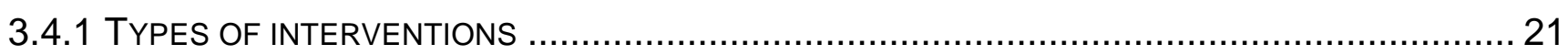

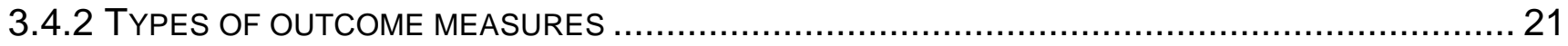

3.5 DATA EXTRACTION AND MANAGEMENT ......................................................... 21

3.5.1 ADVANTAGES AND DISADVANTAGES OF AN ELECTRONIC VERSION (WORD DOCUMENT) OF

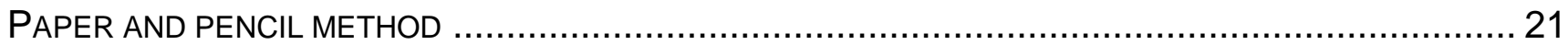

3.6 ASSESSING RISK OF BIAS IN INCLUDED STUDIES........................................... 22

3.7 ETHICAL CONSIDERATIONS RELATED TO DATA COLLECTION........................... 23

3.8 DATA ANALYSIS ........................................................................................... 23

3.8.1 VALIDITY AND RELIABILITY OF THE DATA COLLECTION TOOL AND THE EXTRACTED DATA........ 24

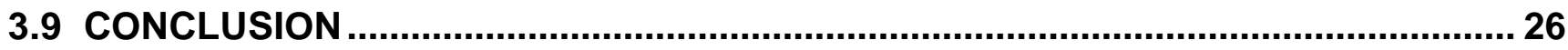




\section{CHAPTER 4}

ANALYSIS, PRESENTATION, AND DESCRIPTION OF THE RESEARCH

\section{FINDINGS}

4.1 INTRODUCTION.................................................................................................. 27

4.2 DESCRIPTION OF STUDIES............................................................................. 27

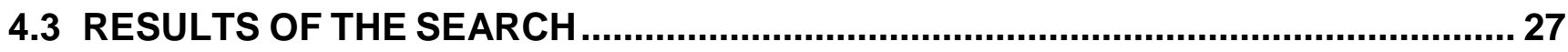

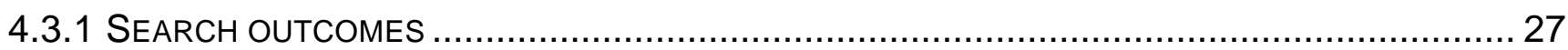

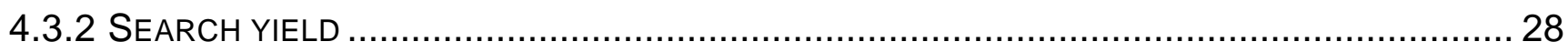

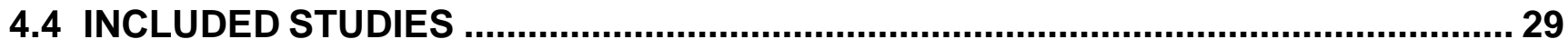

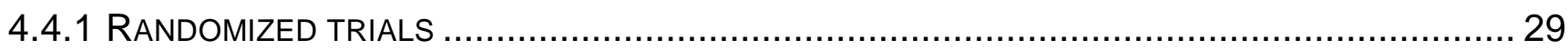

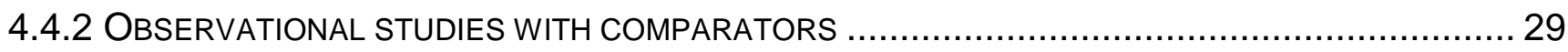

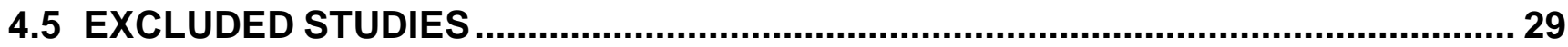

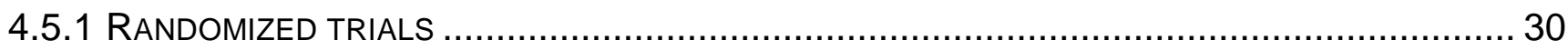

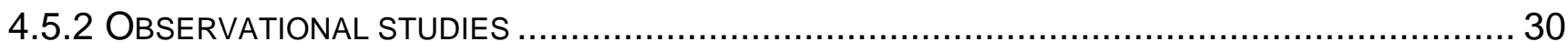

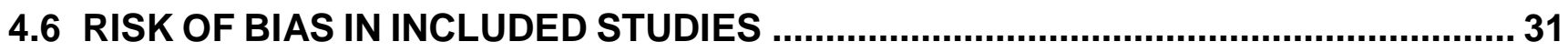

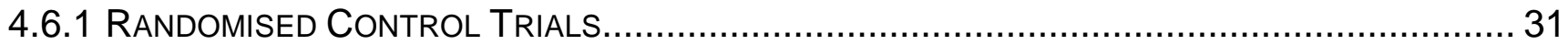

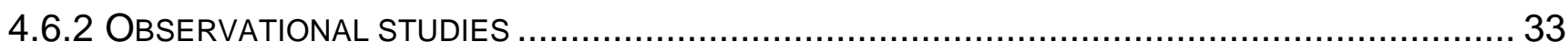

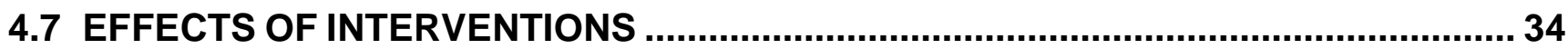

4.7.1 COMPARISON 1: FREQUENT TESTERS ( $\geq 3$ VLS PER YEAR) VERSUS LESS FREQUENT TESTERS

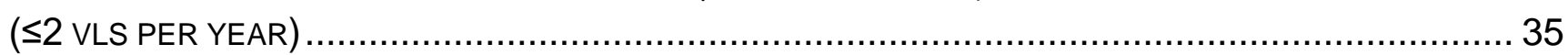

4.7.2 COMPARISON 2: FREQUENT TESTERS ( $\geq 2$ VLS PER YEAR) VERSUS LESS FREQUENT TESTERS

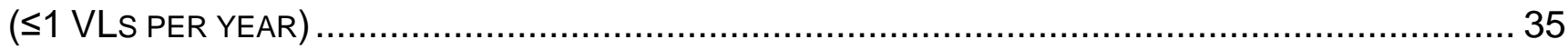

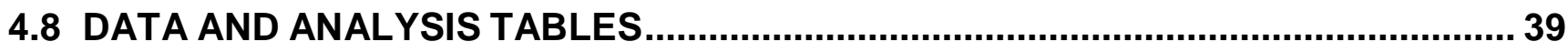

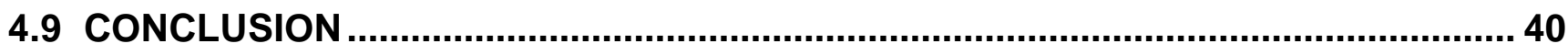

\section{CHAPTER 5}

\section{CONCLUSIONS AND RECOMMENDATIONS}

5.1 INTRODUCTION................................................................................................. 41

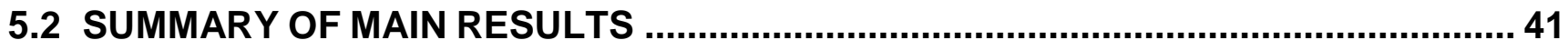

5.3 OVERALL COMPLETENESS AND APPLICABILITY OF EVIDENCE ........................ 43

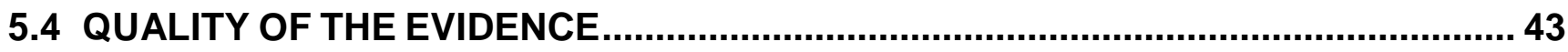

5.5 AGREEMENTS AND DISAGREEMENTS WITH OTHER STUDIES OR REVIEWS ...... 44

5.6 CONCLUSIONS.............................................................................................. 44

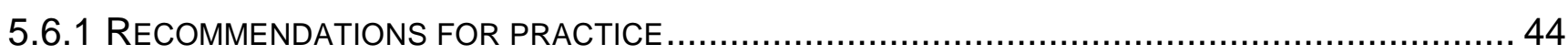


5.6.2 RECOMMENDATIONS FOR RESEARCH 44

5.7 CONTRIBUTIONS OF THE STUDY 45

5.8 LIMITATIONS OF THE STUDY 45

5.9 CONCLUDING REMARKS 46

LIST OF REFERENCES 


\section{LIST OF TABLES}

Table 4. 1 Newcastle-Ottawa quality assessment scale for included observational studies . 34 Table 4. 2 Frequent monitoring ( $\geq 3$ VLs per year) versus less frequent monitoring ( $\leq 2$ VLs per year) 39

Table 4. 3 Frequent monitoring ( 2 VLs per year) versus less frequent monitoring ( $\leq 1$ VLs per year) 


\section{LIST OF FIGURES}

Figure 4. 1 Flow diagram of eligibility criteria of studies

28

Figure 4. 2 Risk of bias graph: review researcher's judgements about each risk of bias item presented as percentages across all included studies

Figure 4. 3 Risk of bias summary: review authors' judgements about each risk of bias item for each included study 32

Figure 4. 4 (Analysis 1.1) Forest plot of comparison: 1 Frequent monitoring ( $\geq 3$ VLs per year) versus less frequent monitoring ( $\leq 2 \mathrm{VLs}$ per year), outcome: 1.1 Virologic failure 36

Figure 4.5 (Analysis 1.2) Forest plot of comparison: 1 Frequent monitoring ( $\geq 3$ VLs per year) versus less frequent monitoring ( $\leq 2 \mathrm{VLs}$ per year), outcome: 1.2 Adherence scores 36

Figure 4. 6 (Analysis 2.1) Forest plot of comparison: 2 Frequent monitoring (2 VLs per year) versus less frequent monitoring ( $\leq 1 \mathrm{VLs}$ per year), outcome: 2.1 Virologic failure 37

Figure 4.7 (Analysis 2.2) Forest plot of comparison: 2 Frequent monitoring (2 VLs per year) versus less frequent monitoring ( $\leq 1 \mathrm{VLs}$ per year), outcome: 2.2 median time for the detection of virologic failure.....

Figure 4.8 (Analysis 2.3) Forest plot of comparison: 2 Frequent monitoring (2 VLs per year) versus less frequent monitoring ( $\leq 1$ VLs per year), outcome: 2.3 Percentage of total personyears spent with virological failure..... 


\section{LIST OF ANNEXURES}

Annexure A: Ethical clearance certificate: Approval of research study by the Higher Degrees Committee of the Department of Health Studies

Annexure B: STUDY ELIGIBILITY SCREENING FORM

Annexure C: DATA COLLECTION TOOL

Annexure D: CHARACTERISTICS OF STUDIES

Annexure E SEARCH STRATEGIES AND RESULTS 


\section{LIST OF ABBREVIATIONS}

\begin{tabular}{ll} 
AIDS & Acquired Immune Deficiency Syndrome \\
ARV & Anti-retroviral \\
ART & Antiretroviral Therapy \\
ACFB & Area About The Change From Baseline \\
CCTG & California Collaborative Treatment Group \\
CD4 & Cluster Of Differentiation 4 \\
CINHAL & Cumulative Index to Nursing and Allied Health Literature \\
CART & Combination Antiretroviral Therapy \\
CI & Confidence Interval \\
DR & Drug Resistance \\
EMBASE & Excerpta Medica dataBASE \\
ENR & Encyclopedia of Nursing Research \\
EPH & Encyclopedia of Public Health \\
ERD & Encyclopedia of Research Design \\
HAART & Highly Active Antiretroviral Therapy \\
HOPS & HIV Outpatient Study \\
HIVDR & HIV-associated drug resistance \\
HIV & Human Immunodeficiency Virus \\
ICER & Incremental Cost-Effectiveness Ratio \\
MD & Mean Difference \\
NNRTI & Non-Nucleoside Reverse Transcriptase Inhibitors \\
NRTIs & Nucleoside and Nucleotide Reverse Transcriptase Inhibitors \\
PI & Protease-Inhibitors \\
QOL & Quality Of Life \\
MDR & Multi-drug Resistance \\
RCT & Randomized Controlled Trial \\
\hline
\end{tabular}


RR Relative Risk

RevMan Review manager

RNA Ribonucleic Acid

SE Standard Error

Sv Sub Verbo which means under the word

TAMs Thymidine Analog Mutations

U.S.A United States of America

UNAIDS United Nations Programme on HIVIAIDS

UNISA University of South Africa

VF Virologic Failure

VL Viral Load

WHO World Health Organisation

WHOLIS World Health Organization Library Information System 


\section{CHAPTER 1}

\section{ORIENTATION TO THE STUDY}

\subsection{INTRODUCTION}

Botswana has continued to expand treatment access while maintaining excellent treatment outcomes for HIV with a view that keeping first line treatment failure rates at a minimum will reduce the overall long-term cost in managing patients. This will be achieved through the interventions focusing on improving adherence as well as early detection and management of antiretroviral (ARV) treatment failure (Botswana Ministry of health 2012:96). Viral load (VL) monitoring remains the gold standard for determining adherence, and antiretroviral therapy (ART) effectiveness. Frequent monitoring enables early and accurate diagnosis of treatment failure before the development of drug resistance mutations, thereby improving the quality of care that HIV patients receive (Roberts et al 2012:1).

According to Kent, McGrath, Loannidis and Bennish (2003:2), the optimal frequency of VL monitoring has not been rigorously determined in randomized trials; and since 2003 some data from randomized trials suggest that virological outcomes may be further improved with even more frequent monitoring. Testing every 3 months rather than every 6 months was associated with modest increases in health outcomes (Bendavid, Young, Katzenstei, Bayoumi, Sanders \& Owens 2008:5). The need to have frequent determination of viral load as currently practiced in resource rich countries has been challenged (Paintsil 2011:6) considering the data reviewed in resource limited settings, indicating little gains in measuring viral load more frequently than every 6-12 months.

A study conducted by Romih, Zidovec, Gedike, Lukas and Begovac (2010:5) in Croatia, a middle income country, , examined patients with less VL testing compared to those with more frequent VL testing. The researchers found contradicting outcomes, and actually suggested that patients with more frequent $V L$ testing were more likely to have virologic failure than patients with less frequent VL testing Romih et al (2010:6). Importantly, it was observed that in a population of patients who were initially virologically well suppressed and considered adherent, there is little if anything to be gained in measuring viral load more frequently than every 6-12 months. According to Romih et al (2010:7) treatment failure was not preceded by less frequent $\mathrm{VL}$ tests, and suggests that considerable savings can be achieved by less 
frequent monitoring of stable patients without compromising the efficacy of the treatment intervention. A question that remains unanswered is whether it is necessary to have frequent viral load determination.

\subsection{BACKGROUND TO THE RESEARCH PROBLEM}

Botswana, a middle-income country with a per capita GDP of $\$ 17,700$ in 2015 (World Factbook 2016) still needs to design appropriate testing intervals. Optimal VL monitoring should lead to more timely detection of treatment failure, more effective, targeted adherence counselling and prevent treatment failure. Estill, Egger, Johnson, Gsponer and Wandeler (2013:1) in their study sought to assess the cost-effectiveness of switching to second-line ART with different monitoring strategies. Additionally, Tucker, Bien and Easterbrook (2013:2), examined optimal monitoring strategies for HIV-infected individuals for outcomes such as, drug resistance, switch rates to second-line ART and adherence. However, these researchers excluded studies that examined only different frequencies of monitoring or thresholds for switching to second-line ART.

In Botswana, the emergence of resistant strains of HIV might have little to do with the lack of health care infrastructure but rather the lack of social support needed for patients to adhere to demanding regimens. Romih et al (2010:1) explain that in well-resourced settings clinical guidelines recommend that viral-load testing be done every 3 months, hence leading to more adherence interventions or early changes in therapy that will reduce the risk of accumulation of resistance mutations.

A study from Khayelitsha, Cape Town found that a first VL at three months rather than six months with targeted adherence interventions for patients with high VL may improve long-term virologic suppression and reduce switches to costly second-line ART (Kerschberger, Boulle, Kranzer, Hilderbrand \& Schomaker 2015:1). Rafiee, Kariminia and Wright (2014:1) have also highlighted that annual viral monitoring could lead to substantial increase in the numbers of failing patients who develop resistance and potentially increasing transmission of drug resistance virus. However, Schneidera, Puthanakit and Kerr (2011:1) argues that less frequent viral load monitoring is likely to provide substantial clinical benefit to HIV-infected patients on ART, and suggest that after a single screening at 6 months, the optimal frequency of viral load monitoring should be annual. In a study conducted by Estill, Aubriere \& Egger (2012:2) using VL monitoring to assess treatment adherence and/or virologic failure, they indicate that 
VL monitoring does not allow detection of non-adherence in real time.

A meta-analysis on these studies will overcome the lack of power and generalizability by combining the findings from studies conducted in varying populations. Intuitively, it is reasonable that the requirement for laboratory monitoring of stable patients might be less frequent, yet there is conflicting data to support this notion. Recognizing the lack of consensus on this subject, the researcher conducted a meta-analysis to investigate the virologic outcomes of infrequent VL testing among clinically and immunologically stable cART-treated patients. Current practice may be based on expert opinions; however, medical decisions should be evidence-based, hence this meta-analysis is likely to be an efficient method of accessing reliable and relevant evidence.

\subsection{STATEMENT OF THE RESEARCH PROBLEM}

Botswana has the opportunity to finally gain epidemiologic control of HIV. The year 2016 has marked an important turning point in the Botswana National HIV Response with the implementation of the New HIV 'Treat All' Strategy (Botswana Ministry of health 2016: 3). According to Estill et al (2012:2), 'Test and treat', which involves large-scale testing for HIV infection and immediate ART, is a subject of debate. In particular, it may be difficult to achieve the necessary high levels of adherence to therapy. Maintaining and monitoring proper adherence to therapy is an increasingly important priority for ART programmes. Kerschberger, et al (2015:1) indicate that, early virologic failure is mainly due to poor adherence and treatment interruptions rather than virologic resistance. According to Kerschberger et al (2015:5) early detection of suboptimal adherence accompanied by targeted adherence interventions may lead to better virologic outcomes. Determining optimal viral load monitoring frequency to detect early adherence problems is essential to maximising the durability of first-line regimens.

Botswana first started the ART Programme in 2002, and it is now poised to become one of the few countries in the world to achieve the UNAIDS 90-90-90 targets. By 2016, Botswana had come close to virtually eliminating Mother-to-Child transmission and had rolled-out ART services to all hospitals and over 600 clinics (Botswana Ministry of health 2016: 3).To maintain this success achieved by up-scaling the coverage of ART, a renewed national consensus on the optimal frequency of viral load monitoring is needed. Currently, the WHO guidelines recommend viral load testing every six months (WHO 2014:76). The Botswana 
Ministry of health (2016:32) recommends laboratory monitoring schedule at 6 months following a 12 months test after initiating ART. The debate over the long-term benefit of various monitoring frequencies still stands. Every monitoring frequency carries different impact on detection of sub-optimal adherence, long-term virologic suppression and rates of switches to costly second-line ART (Keebler, Revill \& Braithwaite 2013:1).

This meta-analysis study seeks to find and summarize evidence on the health outcomes of different virological monitoring frequencies and provide further insights into the acceptability and feasibility of universal testing and treatment in Botswana. Factors associated with the frequency of $V L$ have as yet not been evaluated.

\subsection{PURPOSE OF THE STUDY}

According to Babbie (2007:87-90, the purpose of the study should explain the final conclusions that the research study hopes to reach. The purpose of this study was to evaluate the impact of virologic monitoring frequencies on virologic treatment failure, adherence to therapy, and the emergence of drug resistance in patients infected with HIV. The study attempted to determine the optimal frequency of $\mathrm{VL}$ measurement to optimize patient outcomes and maximize cost-effectiveness.

\subsubsection{Objectives of the study}

In systematic reviews, questions are stated broadly as review 'Objectives', the specific accomplishments the researcher hopes to achieve by conducting the study (Polit \& Beck 2012:93). To guide the study focus, the objectives included ways to obtain answers to research questions.

The objectives for this study were to

- determine the optimal frequency for determining HIV RNA levels

- investigate whether HIV-1 infected patients on a stable and fully suppressive first line regimen could safely be monitored less frequently than the current recommendations of every 3 months.

- evaluate whether frequent viral load monitoring would improve patient adherence and thereby contribute to improved virological outcomes. 


\subsection{RESEARCH QUESTIONS}

A research question is an answerable inquiry into a specific concern or issue. It is essential to a good research design and is the fundamental core of a study. The nature of the research question shapes the research, determines the methodology, and guides all stages of inquiry, analysis, and reporting (Polit \& Beck 2012:55-58). This study sought to answer the following research questions:

- What is the optimal frequency of VL monitoring?

- What are the health benefits of frequent monitoring ( $\geq 3$ VLs per year) versus less frequent monitoring (2 VLs per year)?

- What is the difference in the risk of virologic failure between the frequent monitoring ( $\geq 3$ VLs per year) and the less frequent monitoring (2 VLs per year)?

- What effect does frequency of monitoring has on patient adherence to therapy?

\subsection{SIGNIFICANCE OF THE STUDY}

In the context of implementing the New HIV 'Treat All' Strategy (Botswana Ministry of health 2016:3), which involves large-scale testing for HIV infection and immediate ART, the emergence of HIV drug resistance (DR) is unavoidable. As the number of patients accessing these treatments increases, so will the number of patients who fail them. Less frequently monitored patients are likely to face increased risk of treatment failure, hampering the benefits of the 'Test and treat' strategy. To maintain the success achieved by up-scaling the coverage of ART in Botswana, monitoring frequency of $V L$ testing is based on expert opinion and the recent World Health Organization recommendations. However, medical decisions should be evidence-based.

In Botswana, determination of plasma VL is considered an essential component for monitoring effectiveness of CART and it is performed routinely to confirm virological failure in patients. However, as resources rarely permit, the 2013 WHO guidelines overlay considerable debate about the benefits and frequency of routine viral load testing. When allocating resources, the benefits of any proposed VL testing frequency must balance the risk of virologic failure with the benefits of decreased cost of monitoring. This study investigated whether patients on a stable and fully suppressed regimen could safely be seen less frequently without significant increase in the risk of treatment failure. The financial cost of laboratory diagnostics represents a substantial portion of total health care costs for HIV- 
infected persons. Therefore, less frequent VL monitoring could result in significant reductions in financial costs of laboratory diagnostics, provided that such monitoring strategy is proven to be sufficient and safe. The best interval for routine HIV monitoring has been identified as area in which gaps in knowledge exist. This study could contribute to the body of knowledge to better understand optimal virologic monitoring frequencies for HIV-1 infected individuals.

\subsection{DEFINITION OF CONCEPTS}

Concepts may refer to theoretical creations that are based on observations which cannot be observed directly or indirectly (Babbie 2007:43). Babbie (2007:44) further defines concepts as "basic building blocks of theory", that are abstract elements representing classes of phenomena within the field of study. In Alston (2003:39), concepts are terms which usually summarises clusters of related elements. According to Babbie (2007:110), the process of classifying and specifying perceptions or experiences by use of particular terms in research is called conceptualization. Conceptualization is the process of coming to an agreement about what the terms mean, and then produce a specific, agreed-on meaning on a concept for purposes of a particular research. Polit and Beck (2012:30) summarises the definition of concepts as constructs derived by mutual agreement from mental representation of some phenomenon (conceptions).

For the purposes of this study, it was necessary to specify exact meanings for all concepts. The following concepts related to this study were identified and described to clarify in advance what they mean in order to draw meaningful conclusions about them and indicate how variables were observed and measured (Babbie 2007:110; Polit \& Beck 2012:30).

\subsubsection{Adherence}

Adherence refers to the willingness and ability of patients to follow health-related advice, take medication as prescribed, attend scheduled appointments, and complete recommended investigations (Moosa \& Jeenah 2012:144). In this study, adherence means the ability of the patient to take medication as prescribed and then self-report using a validated adherence tool. The adherence was measured either as a score or a rate, which is the number of doses taken, divided by the number prescribed.

\subsubsection{Anti-retroviral (ARV) drugs}

Anti-retroviral (ARV) drugs are drugs that reduce the level of HIV in the patient. Classified 
according to their mechanism of action, different groups of ARVs in use include Fusion Inhibitors, Non-Nucleoside Reverse Transcriptase Inhibitors(NNRTI), Nucleoside and Nucleotide Reverse Transcriptase Inhibitors (NRTIs), Protease-Inhibitors (PI) (EPH 2008, sv "Antiretroviral Medications").

\subsubsection{Evaluation}

An evaluation typically reviews and investigates how well a specific program, practice, or intervention is working. Generally, the term evaluation research is used when researchers are trying to determine the effectiveness of a rather complex program, rather than when they are testing a specific entity. Moreover, evaluations often try to answer broader questions than simply whether an intervention is more effective clinically than care as usual. There are various types of evaluations. Cost-benefit analyses are typically done in connection with impact and outcome analyses (Polit \& Beck 2012:192-193, 410). Evaluation in this study refers to an investigation on the virologic and treatment outcomes when viral load is measured frequently compared less frequent monitoring, among HIV-infected patients on a stable regimen. This is to determine the impact of changing monitoring from frequent to less frequent monitoring, and to determine the most efficient and effective monitoring strategy.

\subsubsection{First-line treatment}

First-line treatment is the primary treatment regimen or regimens that are generally accepted by the medical establishment for initial treatment. In Botswana, it is common practice to use a combination of Truvada and Dolutegravir for new and previously initiated adults, pregnant women, and adolescents (>40kg) (Botswana Ministry of health 2016:16). These are either Protease inhibitors (PI) or Non-Nucleoside Reverse Transcriptase Inhibitors (NNRTIs)-based HAART fist-line regimen.

\subsubsection{Frequency of monitoring}

Frequency of monitoring refers to viral load measurements aimed at detecting changes in the health status of populations (eg, every 3, 6, 12, or 24 months) after initiating ART (A Dictionary of Epidemiology 2008, "monitoring"). In this study frequent monitoring is considered to be $\geq 3$ VLs per year and the less frequent monitoring is 2 VLs per year.

\subsubsection{Human Immunodeficiency Virus (HIV)}

Human Immunodeficiency Virus (HIV) is a retrovirus that primarily infects vital components of the human immune system and is the virus that causes AIDS (EPH 2008, sv "AIDS"). 


\subsubsection{HIV-1 Infected Patients}

According to ENR 2006, Sv "Population Genetics and Human Health", infection with the human immunodeficiency virus type 1 (HIV-1) is associated with progressive and profound loss of immune function that places infected patients at risk for opportunistic infections, malignancies, and death.

\subsubsection{Meta-Analysis}

Meta-analysis is a technique for integrating quantitative research findings statistically, where the findings from a study are treated as one piece of datum. The findings from multiple individual studies (similar with respect to population, outcome and intervention) focused on a specific research question are then combined to create a data set that can be analysed in a manner similar to that obtained from individual studies. Thus, instead of study participants being the unit of analysis, individual studies are the unit of analysis in a meta-analysis. The essence of a meta-analysis is the calculation of a common metric; an effect size with a confidence interval for every study. The effect size represents the magnitude of the impact of an intervention on an outcome, or the degree of association between variables (Polit \& Beck 2012:120).

\subsubsection{Treatment failure}

Treatment failure is defined as a persistent virological failure (Botswana Ministry of health 2016:20). In this study treatment failure is considered to be two successive VLs of $>200$ copies/ml.

\subsubsection{Responses to Antiretroviral Therapy}

Responses to Antiretroviral Therapy (ART) is explained as health outcomes susceptible to direct measurement which reflects the state of health of persons, like treatment failure of first-line HIV regimens demonstrated by virologic failure (A Dictionary of Epidemiology 2008, "health indicator"). In this study, the response to antiretroviral therapy could either be viral suppression or treatment failure. The secondary outcomes include the time for the detection of virologic failure and the person-years spent with virological failure.

\subsubsection{Viral Load (VL)}

Viral Load (VL) is a measure of the level of the virus in HIV infected patients. It is measured at six months post initiation of ART and six monthly thereafter (Botswana Ministry of health 2016:32). 


\subsubsection{Virologic failure (VF)}

Virologic failure is described as viral load $>400$ copies $/ \mathrm{ml} 6$ months after ART initiation or viral load rebound to $>400$ copies $/ \mathrm{ml}$ after documented full suppression. In Botswana, documented virologic suppression to $<400 \mathrm{copies} / \mathrm{mL}$ as confirmed by two priority viral loads tests (Botswana Ministry of health 2016:20).

\subsubsection{Virologic Monitoring Frequencies}

This is the rate of intermittent testing and analysis of measurements aimed at detecting changes in the quantity of viral load copies $/ \mathrm{ml}$. The frequency is the number of occurrences of a repeating Virological test (detecting the presence of viral nucleic acid) per unit time. A frequent VL testing would be ( $\geq 3$ VLs per year) and a less frequent schedule would be ( $\leq 2 \mathrm{VLs}$ per year) (Bendavid et al 2008:1). In this study, two comparison groups emerged being guided by the virologic monitoring frequencies:

- Group 1: Frequent monitoring ( $\geq 3$ VLs per year) versus less frequent monitoring ( $\leq 2$ VLs per year)

- Group 2: Frequent monitoring (2 VLs per year) versus less frequent monitoring ( $\leq 1$ VLs per year)

\subsection{FOUNDATIONS OF THE STUDY}

Polit and Beck (2012:132) indicate that the theoretical foundation of the study is seen as the rationale to enhance the utility of a study. The authors further mention that it is difficult to see how a theory would enhance the value of the findings of a research that has a utilitarian goal (Polit \& Beck 2012:133). This study focused on the right and wrong of health outcomes (consequences) of choosing one VL monitoring frequency over other VL monitoring frequencies. The study was designed to determine the optimal viral load monitoring frequency to detect early adherence problems as an attempt to maximise the durability of first-line regimens.

Viroligic failure is a critical health outcome and taken as a variable because it varies with specific conditions. The study sought to understand the system of variables that cause this particular health outcome to be occurring when one VL monitoring frequency is chosen over another. The studies of interest were treated as the "carriers" of the variables. Variables, in turn have attributes (categories or values). Babbie (2007:10-11) describes attributes as characteristics or qualities that describe an object. Variables are logical groupings of 
attributes. Treatment failure as a health outcome can be categorized as virologic failure, immunologic failure, clinical failure, or some combination of the three. Almost all antiretroviral (ARV) management decisions for treatment failure are based on addressing virologic failure (indicated by plasma viral load limits). Virologic treatment failure may be due to drug resistance which may also develop if a person cannot tolerate a drug or has poor adherence. Furthermore, Babbie (2007:14) indicates that sometimes attributes can be thought of as categories that make up a variable. Thus for example, $\geq 3$ VLs per year and $\leq 2$ VLs per year are attributes and monitoring frequency is the variable composed of the two attributes.

\subsection{INTRODUCTION TO RESEARCH DESIGN AND METHODOLOGY}

Scientific inquiry is dedicated to making observations and interpreting what is observed. A study design is a plan that determines what to observe and analayse, why and how (Babbie 2007:84). According to Polit and Beck (2012:144) study design is the overall plan for addressing a research question, including specifications for enhancing the study's integrity. Methodology is the technique used to structure a study and to gather and analyze information in a systematic fashion in order to achieve an intended goal (Polit \& Beck 2012:422).

A quantitative approach was followed. Quantitative research adopts the positivist paradigm of research. This traditional paradigm underlying the scientific approach was appropriate for this study as it assumes that there is a fixed, orderly reality that can be objectively studied and proven (Polit \& Beck 2012:419). In this study, a correlation between the variables was examined to compare the health outcomes (dependent variable) of patients when virlogic monitoring frequency varies (independent variable)

A descriptive systematic review and meta-analysis was conducted. A number of studies of the same intervention have since been published (Bendavid et al 2008:5; Kerschberger et al 2015:10; Romih et al 2010:1; Schneidera et al 2011:1;Rafiee et al 2014:1). A systematic review and meta-analysis was required to determine consistency among these studies. This settled controversies arising from these apparently conflicting studies. The degree of data inconsistencies was formally assessed, and reasons for different results were explored and quantified. According to Nieswiadomy (2012:76) meta-analysis statistically combines the results of several studies that have examined the same topic. In this study, several research 
studies were simultaneously examined using statistical measures. The results of different studies were combined and statistically analysed.

\subsubsection{Study setting and population}

According to Polit and Beck (2012:27, 423), a study setting is the specific place where data collection occurs. It ranges from naturalistic (field) settings to formal laboratories and conditions in which data collection takes place in a study. The published articles relating to this study were located using the Medline system, supplemented by the use of other indices such as UNISA online libraries, the Cochrane Library, CINHAL, EMBASE and World Health Organization (WHOLIS) library database, Web of Science, PsycINFO, PubMed and Google Scholar. Specific investigators active in the area of interest were consulted to find unpublished studies. Peers and Experts were consulted in an attempt to identify all relevant studies. A population is all the individuals or objects with common, defining characteristics indicating what attributes the participants or subjects should possess, and thereby clarifying the group to which the study results can be generalized (Polit \& Beck 2012:46). The population for this study was all published articles focusing on HIV Viral Load Monitoring Frequency on HIV-1 patients. The target population for this study was studies identified from January 2006 to August 2016; with no geographic restrictions.

\subsubsection{Sample and Sampling Methods}

According to Babbie (2007:184), a sample is a subset of a larger population from whom information is gathered, and sampling is the process of drawing a fair representative portion from the population. A purposive or judgmental sampling method was used on the basis of the knowledge of the population, its elements, and purpose of the study.

Relevant studies were identified with search terms including "viral load monitoring", "drug resistance", "treatment adherence", and "virologic failure". The sample of selected studies included only those which examined the frequency of VL testing and the association with health outcomes (treatment failure, adherence, drug resistance). Potentially relevant titles were identified through database searching and other sources. Studies meeting eligibility for inclusion were subjected to meta-analysis. The inclusion criteria are described in detail in chapter 3.

\subsubsection{Data collection}

The concepts in which researchers was interested were measured, observed, and recorded. 
Data collection dealt with the observational aspect of the study and the process of obtaining the sample and collecting data for the study (Babbie 2007:37; Polit \& Beck 2012:48). This study, being a Meta-analysis involved and relied on existing available data gathered in previous studies.

A standardised data collection form was used in the extraction process. Data were extracted on the following: study name; authors; antiretroviral combinations used; year of publication or presentation; study design categorised according to whether cohort, part of a clinical trial, or patients were randomised to particular treatment; participant characteristics (age); definition of virological failure; and numbers of virological failures with viral load greater than 400 copies per $\mathrm{ml}$. Furthermore, resistance data for virological failures were extracted. There was no form of human intervention (treatment or medical related procedures) involved in this study. According to Kimberlin and Winetrstein (2008:3) the three basic approaches to validity are content validity, construct validity, and criterion-related validity. The most valid instrument has both external validity and content validity. External validity is the extent to which the results of a study can be generalized from a sample to a population. Content validity refers to the appropriateness of the content of an instrument (Kimberlin and Winetrstein 2008:4). The validity and reliability of the instrument was achieved through a pretest of the instrument, focus of the questions on the content of the subject under investigation, review of the tool by the supervisor. More information on reliability and validly of the data collection tool is presented in chapter 3. There were no copyright issues as the instrument was self-designed. More details on data collection and ethical considerations are discussed in chapter 3 .

\subsubsection{Data analysis}

Polit and Beck (2012:278) indicate that data collected in a study do not by themselves answer research questions or test hypotheses. Data were systematically analyzed to detect patterns. Data analysis was devoted to the organization and analysis of research data. According to Babbie (2007:37), data analysis looks for meaningful patterns observed among variables and where appropriate, compares what is logically expected with what is actually observed. Techniques for combining indicators into composite measures of variables, i.e Indexes and scales were developed by Quantitative data analysts (Babbie 2007:180). Quantitative data analysis could be a univariate analysis, which involves one variable, or bivariate analysis which involves two variables or multivariate analysis, the simultaneous examination of several variables (Babbie 2007:432). 
Collected and coded data were uploaded to analytical computer software Excel for statistical analysis. For each comparison of monitoring frequencies, the study reported the estimated relative risks (RR) and the 95\% confidence interval (Cl) for all key outcomes for each of the studies. Random effects model were used to generate a summary effect size, should it be appropriate to pool research findings that compare the same monitoring strategies and report comparable health outcomes. The outcomes to be examined included drug resistance, switch rates to second-line ART and treatment adherence. Estimates of group means (and SEs) of baseline variables (age, log10 viral load) was calculated using inverse variance weights. Studies were stratified for analysis into those with intensive monitoring (more frequently than 3 months), and those with infrequent (less frequently than every 3 weeks). After studies are stratified into two groups by viral-load monitoring intensity (infrequent vs frequent), health outcomes were compared. Reliability of data is explained in chapter 4.

\subsection{STRUCTURE OF THE DISSERTATION}

The structure of the dissertation is as follows:

Chapter 1: Overview of the study

Chapter 2: Literature review

Chapter 3: Research design and methods

Chapter 4: Analysis, presentation, and description of the research findings

Chapter 5: Conclusion and recommendations

\subsection{CONCLUSION}

This chapter highlighted an overview of this study with special emphasis on the background and problem statement, and the purpose of the study. The objectives and significance of the study were outlined and the research methodology was introduced. The next chapter, chapter 2, presents the literature review. 


\section{CHAPTER 2}

\section{LITERATURE REVIEW}

\subsection{INTRODUCTION}

A literature review typically summarizes results of past studies, suggests potential reasons for inconsistencies in past research findings, and directs future investigations. Traditional narrative reviews identify articles relevant to the topic of interest, examines the results of each article to see whether the hypothesis was supported, and provides an overall conclusion. Recently, systematic research syntheses that include meta-analyses have taken the place of purely narrative reviews of empirical literature to address many limitations of the narrative review by using statistical procedures to combine the results of previous studies (Alasuutari, Bickman \& Brannen 2008:536).

This chapter briefly deliberates on the monitoring frequency in viral load monitoring, and its outcomes. Several studies have investigated whether HIV-infected patients on a stable and fully suppressive combination antiretroviral therapy (CART) regimen could safely be monitored less often than the current recommendations of every 3 months (Bryant, Smith \& Keiser 2013:1; Caniglia, Sabin, Robins, Logan, Cain \& Hernán 2016:1; Haubrich, Currier, Forthal, Beall, Kemper, Johnson, Dube, Hwang, Leedom, Tilles \& McCutchan 2001:1; Reekie, Mocroft, Sambatakou, Machala, Chiesi, Lunzen, Clumeck, Kirk, Gazzard \& Lundgren 2008:1; Romih et al 2010:1; Schneider et al 2011:1; Weissman, Singh, Dykema \& Parker 2016:1; Young, Hart, Buchacz, Scott, Palella \& Brooks 2015:1).

\subsection{MONITORING FREQUENCY}

According to Weissman (2016:1), people infected with HIV require life-long care. Therefore, it is important to consider more effective treatments and determine an updated monitoring frequency. The aim of routine frequent $V L$ testing in patients with undetectable $V L$ is to detect virological failure early, leading to adherence interventions or early changes in therapy that will limit ongoing viral replications and reduce the risk of accumulation of resistance mutations (Romih et al. 2010:7). Current guidelines for HIV management recommend monitoring plasma HIV-1 RNA level every 3-6 months in patients on a stable 
antiretroviral regimen (Chaiwarith, Praparattanapan, Nuntachit, Kotarathitithum, Sirisanthana \& Supparatpinyo 2011:1).

A randomized clinical trial by Weissman (2016:5) explored the optimal frequency of HIV monitoring needed in stable patients with HIV and on ART, and the findings suggest that less frequent monitoring may be considered for adherent patients who have VL suppression of 2 years with VLs conducted every 6 months. Caniglia et al (2016:1) reports that monitoring frequency of virologically suppressed individuals can be decreased from every 3 months to every 6, 9, or 12 months. According to Young et al (2015:7), biannual VL monitoring for the qualifying patients could greatly save costs without jeopardizing patient safety. This could help allocate the saved resources to expand and improve other areas of HIV care and management.

The cost-effectiveness and cost-utility of different frequencies of monitoring plasma viral load among HIV positive children initiating ART in a resource-limited setting has been investigated (Schneider et al 2011:6) and the optimal frequency of VL monitoring was found to be annual, after a single screening at 6 months. Therefore, infrequent VL monitoring is likely to provide substantial clinical and financial benefit. However, this is in disagreement with the findings in Haubrich et al (2001:6) who report that frequent VL monitoring of every 2 months results in better treatment management, and significant improvements in HIV virus load suppression, compared with infrequent monitoring of twice yearly. The clinical consequences of delaying ART switching and allowing ongoing virological failure are likely to be serious. Reekie et al (2008:7) says that patients who have spent less time with uncontrolled viraemia while on CART were less likely to experience treatment failure.

\subsection{VIROLOGIC FAILURE}

Weissman et al (2016:3) defines virological failure as two successive VLs of $>200$ copies/ml, and confirms that among virally suppressed persons with HIV, there are no differences in virologic failure after 24 months on ART. Young et al. (2015:1) sought to assess whether viral load (VL) monitoring frequency was associated with differential rates of virologic failure (VF) among HIV Outpatient Study (HOPS) participants and did not detect statistically significant difference in frequency of VF among patients undergoing frequent versus less frequent $V L$ testing even after multivariable adjustment. Therefore, having infrequent monitoring may not be associated with an increased rate of VF as compared with frequent 
monitoring. Furthermore, Chaiwarith et al. (2011:1) found no difference in virologic failure after 24 months, among HIV-infected patients who had VL monitoring every 4 months versus every 6 months. Additionally, reducing the monitoring frequency is likely to detect virologic failure almost as frequently as using standard 6-month monitoring (Bryant et al 2013:3).

However, these findings conflict with the data found in Caniglia et al (2016:5), a study that compared VL monitoring strategies with respect to virologic outcomes, focusing on the HIVCAUSAL Collaboration, which includes prospective cohort studies from 6 European countries and the United States. Caniglia et al (2016:5) finds that monitoring every 9-12 months increases the risk of virologic failure compared with monitoring every 3 months. Haubrich et al (2001:2) reports that more frequent VL monitoring results in a reduction in virus load nearly twice than seen with less frequent virus load monitoring. Therefore, a statistical strategy for assembling the results of these separately conducted studies, sometimes with conflicting findings would be necessary to decide on the optimal VL frequency.

\subsection{ADHERENCE}

Visits for monitoring purposes are often used as opportunities to reinforce the need for treatment adherence and decreased monitoring may affect adherence rates. According to Reekie et al (2008:8) it is possible that less frequent monitoring will result in poorer adherence, in turn leading to a higher risk of treatment failure. The findings for virologic failure in Caniglia et al (2016:7) might reflect intermittent or poor adherence among individuals monitored less frequently. It is reasonable to think that more frequent VL would improve patient adherence and thereby contribute to improved virological outcomes. However, in a randomized clinical trial conducted by Weissman et al (2016:2), there was a difference in adherence scores with regards to VL monitoring frequency. This data is similar to data reported in Haubrich et al (2001:6); another randomized study that evaluated whether more frequent VL monitoring might motivate patients to improve adherence to their therapy, and the trial found that the frequent group did not have better adherence than the infrequent group.

\subsection{DRUG RESISTANCE}

According to Reekie et al (2008:8), infrequent VL makes patients to spend longer with detectable viraemia before it is identified, thus increasing the risk of developing resistance. 
Haubrich et al (2001:7) indicates that better outcomes observed in the frequent group may have been due to earlier detection of loss of virological control and to more rapid treatment adjustments that prevented the development of antiretroviral resistance. Less frequent monitoring of patients on ART may be associated with resistant mutations. However, in Weissman et al. (2016:4) there are no statistically significant differences between the less frequent and frequent monitoring groups on development of new resistant mutations. In another study, the median time of exposure to replicate virus was found to be 147 days, which is well below the median time for the development of Thymidine Analog Mutations (TAMs) in clinical trials of 594 days (Bryant et al 2013:3). Therefore, infrequent monitoring may not increase the risk of developing resistant virus, particularly TAMs.

\subsection{CONCLUSION}

Literature has shown that HIV-infected persons who have access to medical care and are prescribed combination antiretroviral therapy (CART) are increasingly living longer and experience lower rates of treatment failure (Young et al 2015:1). The studies were conducted in specific type of populations and this affects generalizability. The next chapter presents the research design and methodology. 


\section{CHAPTER 3}

\section{RESEARCH DESIGN AND METHODOLOGY}

\subsection{INTRODUCTION}

According to Polit and Beck (2012:24), research methods refers to the techniques researchers use to structure a study and to gather and analyze information relevant to the research question(s). Rigorous methodological procedures aim to eliminate or minimize bias, or to detect its presence to take into account in interpreting the data and enhance the quality of the study findings (Polit \& Beck 2012:12, 35). This chapter explains how this study was planned, structured and executed. The subjects' inclusion and exclusion criteria, search strategy for studies, data collection, and measures to evaluate the risk of bias of included studies are discussed.

This study's purpose was to evaluate the effects of frequency of virologic monitoring on virologic failure, adherence to therapy, and drug resistance as a response to ART therapy in patients infected with HIV-1. This was achieved by evaluating studies that were deemed eligible for this research.

\subsection{ELIGIBILITY CRITERIA}

Eligibility criteria are the specific characteristics that delimit the study population. This covered substantive methodologic factors and stipulated the specific variables or phenomena to be studied (Polit \& Beck 2012:204, 386). This study focused on randomized trials. However, it included other studies regardless of quality and incorporated information about quality into the analysis; such as observational studies with comparators, cohort studies, controlled clinical trials and case-control studies. Therefore the inclusion and exclusion characteristics of the studies were considered as follows:

\subsubsection{Inclusion criteria}

Inclusion criteria are a set of predefined characteristics used to identify subjects to include in a research study (ERD 1964, sv "Inclusion criteria"). The inclusion criteria were as follows: Studies 
- pertaining to Viral load monitoring of antiretroviral therapy,

- on resistance to antiretroviral drugs used to treat HIV and AIDS.

- which evaluated virologic monitoring frequency and primary health outcomes

- that examined virologic failure, drug resistance, switch rates to second-line ART and adherence.

- that evaluated the frequency of viral load monitoring after initiation of ART and its effects on virologic and treatment outcomes.

- that examined different frequencies of monitoring or thresholds for switching to second-line ART, optimal frequency of monitoring.

- must have primary comparisons of the frequency of viral load monitoring strategy.

- of comparisons of particular interest on virologic monitoring.

- should have treatment outcomes such as treatment failure, adherence, and drug resistance measurements related to the effects of monitoring frequency.

- are observational studies (cohort and case-control) which included comparators.

- with populations that include ARV-naive, ARV-experienced or a combination of these without restriction on age, ethnicity, race, and nationality.

- with specific population of HIV-1 infected patients that were initially virologically well suppressed, on ART that must include either a NNRTI or PI as part of their treatment regimen.

- only in English language.

\subsubsection{Study exclusion criteria}

Exclusion criteria specify the characteristics that ruled out certain subjects not to be included in the study because they did not possess or meet the inclusion criteria (Polit \& Beck 2012:274). The exclusion criteria were as follows:

- Letter, editorial, non-systematic review, observational studies without comparators, case report, cross-sectional study design.

- Studies evaluating ART in patients who have failed more than one regimen.

- Studies evaluating substituting ART due to toxicities rather than switching ART due to clinical, immunologic, or virologic failure.

\subsection{SEARCH FOR STUDIES}

The search was on original articles with online accessible full text available in database and pre-selected online data base. 


\subsubsection{Electronic Searches}

Using search terms appropriate for each database, the researcher used the HIV and AIDS Cochrane Collaborative Review Group search strategy to design a structured, comprehensive and exhaustive search strategy in an attempt to identify all relevant studies regardless of publication status. The researcher performed a computer-assisted search in MEDLINE, EMBASE, and Cumulative Index of Nursing and Allied Health (CINAHL) via EBSCO from 2006 to 3 July 2017. The researcher identified grey literature through the Science Citation Index from 2006 to 3 July 2017. In addition, the researcher searched the UNISA online libraries, the Cochrane Library, and World Health Organization (WHOLIS) library database. The searches were performed without limits to setting or age; but were limited to studies published in English language from 2006 to 3 July 2017. Keywords used for database searching included the following; virological monitoring, virologic treatment failure, adherence and therapy, viral load testing, HIV-1 drug resistance, first-line antiretroviral therapy and adherence treatment failure, switch and monitoring.

\subsubsection{Searching other resources}

The researcher screened reference lists of all included studies identified by the above methods to identify potential and eligible studies missed by electronic searches. Additional studies were searched using the 'Related Articles' feature through PubMed. The researcher aimed to access theses and dissertation abstracts from institutions known to be involved in research regarding virologic responses to antiretroviral therapy in HIV-1 infected patients. The researcher also contacted researchers involved in studies with possibly relevant but unpublished data to locate relevant data.

\subsection{SELECTION OF STUDIES}

The literature search was conducted with the assistance of the UNISA Information Search Librarians. The researcher screened all titles and abstracts of identified studies from searches of electronic databases to determine whether they met the inclusion criteria. This initial screen removed all titles which did not fit the inclusion criteria. For each potentially eligible study identified by the electronic search or by other methods, the full-text version was obtained for further assessment. Each study was evaluated for inclusion or exclusion using a study eligibility screening form based on pre-specified inclusion criteria (Annexure B). 


\subsubsection{Types of interventions}

This study looked for studies with primary comparisons of the frequency of viral load monitoring strategy. Comparisons of particular interest were infrequent monitoring ( $\leq 2$ VLs per year) versus more frequent virologic monitoring ( $\geq 3 \mathrm{VLs}$ per year), and the role of adherence monitoring in these comparisons.

\subsubsection{Types of outcome measures}

This study included studies that assess the optimal virologic monitoring frequency and its effects on virologic outcomes. Treatment failure, adherence, drug resistance measurements related to the effects of monitoring frequency were included as outcomes.

\subsection{DATA EXTRACTION AND MANAGEMENT}

Data were extracted from the selected studies using a standardized data-extraction sheets in "pen-and-pencil" forms (or the electronic equivalent) (Annexure $\mathrm{C}$ ), and the meta-analysis was performed. The type of tool used for data extraction was a paper and pencil modified into an electronic version (word document). All relevant data were transferred to other electronic platforms like the Cochrane's statistical software, RevMan v5.3, for computerassisted statistical analyses. Data extracted included:

- Study details such as citation, study design, type, start and end dates, country and location of study (e.g. higher income vs. lower income country).

- Assessment of methodological quality

- Possible sources for heterogeneity

- Participant details which included study population eligibility (inclusion and exclusion) criteria, ages, population size, and attrition rate, relevant baseline characteristics (e.g. treatment naive or experienced).

- Interventions details, e.g. frequency of Virologic monitoring

- Outcome details, e.g. HIV-RNA viral load measurements and proposed levels for suppression as defined by the authors, adherence, and resistance.

\subsubsection{Advantages and disadvantages of an electronic version (word document) of Paper and pencil method}

In a study by Elamin, Flynn, Bassler, Briel, Alonso-Coello and Karanicolas (2009:1) some 
data-extraction tools for conducting systematic reviews were assessed. They provided guidance about choice of data extraction tools such as paper and pencil, spreadsheets, webbased surveys, electronic databases, and web-based specialized software. Each tool offers benefits and drawbacks (Elamin et al 2009:3). The advantages of the paper and pencil were as follows:

- "Pen-and-pencil" forms (or the electronic equivalent) carried a relatively low cost of implementation and use (no need for computer programming or specialist software).

- The method was suited for this small local project (few primary studies included, with only one reviewer).

- It was easy to set up or contextualise the data extraction form to be most compatible with the research to facilitate data management.

- No training was required and less time was needed for the researcher to get familiar with the tool and use it efficiently to input data.

- The electronic versions could be shared with the supervisor of this study through an e-mail (portability and accessibility).

- The method was useful during pre-test of data extraction items and procedures.

On the other hand, the disadvantage of paper and pencil was that it took a lot of time to transfer data to the electronic platform for computer-assisted statistical analyses.

\subsection{ASSESSING RISK OF BIAS IN INCLUDED STUDIES}

Kimberlin and Winetrstein $(2008: 6,7)$ indicate that a bias is a systematic error in results or inferences, which can lead to underestimation or overestimation of the true intervention effect. It was important to assess the risk of bias in all the studies in the review irrespective of the anticipated variability in either the results or the validity of the included studies. This appraisal process was the assessment of risk of bias in the included studies.

The researcher assessed the methodological quality of each study being guided by the Cochrane Collaboration domain-based evaluation tool which contains items that are directly related to internal validity. The relevant domains in the 'risk of bias assessment' a component of Annexure C were sequence generation, allocation concealment, blinding, incomplete outcome data, selective outcome reporting, and other potential biases. The 
domains were evaluated for assessment of the selection bias, performance bias, detection bias, attrition bias, and reporting bias as explained as follows:

- Selection bias: for systematic differences between baseline characteristics of the groups that are compared.

- Performance bias: for systematic differences between groups in the care that was provided, or in exposure to factors other than the interventions of interest.

- Detection bias: for systematic differences between groups in how outcomes were determined.

- Attrition bias: for systematic differences between groups in withdrawals from a study causing incomplete outcome data.

- Reporting bias: for systematic differences between reported and unreported findings. The researcher assessed each of the above domains as low risk of bias (low), high risk of bias (high), or uncertain risk of bias with correspondent judgment criteria (see Annexure C).

\subsection{ETHICAL CONSIDERATIONS RELATED TO DATA COLLECTION}

According to Polit and Beck (2012:89), ethical considerations are systems of moral values that efforts to maintain high standards of integrity and avoid such forms of research misconduct as plagiarism, fabrication of results, or falsification of data. To comply with the expected ethical considerations, Ethical clearance (Annexure A) was obtained from the Research and Ethics Committee of the Department of Health Studies, University of South Africa and the researcher waited for the permission from the supervisor to proceed with data collection after the methodology chapter was approved. Permission to review the records was not necessary as all the studies were open access and obtained online from free websites. Data was collected and synthesised from from previous studies in which informed consent had already been obtained by the researchers.

\subsection{DATA ANALYSIS}

According to Paterson, Thorne, and Canam (2003:55-69) data-analysis in meta-analysis means the comparative analysis of research findings of primary research studies conducted by a variety of researchers. This is the analysis of "processed data" from selected research studies to create a systematically developed, integrated body of knowledge about a specific phenomenon. The process involved the comparison of each individual study with all other 
studies that had a common focus.

\subsubsection{Validity and reliability of the data collection tool and the extracted data}

According to Kimberlin and Winetrstein (2008:1) measurement involves the operationalization of the constructs in defined variables and the development and application of instruments or tests to quantify these variables. The key indicators of the quality of a measuring instrument are the reliability and validity of the measures. The researcher used the following steps to improve the data collection tool and the extracted data:

\subsubsection{Reliability}

Reliability is the accuracy of an instrument or the extent to which a data collection tool consistently has the same results if it is used in the same situation on repeated occasions. To extract the findings from each study in a consistent manner, data were measured and collected consistently according to standard definitions and methodologies (Kimberlin \& Winetrstein 2008:1-2). The researcher structured the data entry in a logical manner and was consistent in the order and style of description of the information for each included study. When constructing reliable data collection instruments the researcher:

- Ensured that the questions and the methodology are clear by using research steps that are clearly explained and easy to follow for anyone to redo the procedure.

- Used explicit and straightforward definitions of concepts.

- Used already tested and proven Data Collection Form for RCTs \& Non-RCTs from the Cochrane Library, available from http://airways.cochrane.org/resources-andinformation. The form was used as a guide for developing own data extraction form, and permission to use the form was not necessary as all forms were open access and obtained for free from Cochrane website.

- Was informed by the purpose of the study to develop the method of data extraction.

- Recorded any missing information as unclear or not described, to make it clear that the information was not found in the study report(s).

\subsubsection{Validity}

According to Kimberlin and Winetrstein (2008:1), the extent to which the study can draw conclusions about the effects of an intervention depends on whether the data and results from the included studies are valid. In Polit and Beck (2012:34) the first dimension of validity 
looks at the external validity and questions whether there is evidence to support the assertion that the methods are really measuring the abstract concepts that they purport to measure. The second dimension is the internal validity, relates to whether the study answers its research question 'correctly', that is, in a manner free from bias. Kimberlin and Winetrstein (2008:1), define validity as the extent to which a tool measures what it intends to measure.

Validity requires that an instrument be reliable. Validity is not a property of the test itself. Instead, validity is the extent to which the interpretations of the results of a test are warranted, which depends on the test's measurement of the underlying construct (Kimberlin \& Winetrstein 2008:4). This research involved quantifying attributes that could not be measured directly. Abstract concepts (constructs), such as treatment failure, health outcomes, and adherence to ARV regimens are measured. These constructs can only be inferred from observations of specific measurements that are thought to be indicators of the presence of the construct.

Likewise, in this study, treatment failure was measured as Viral load $>400$ copies $/ \mathrm{ml} 6$ months after ART initiation or viral load rebound to $>400$ copies $/ \mathrm{ml}$ after documented full suppression. When constructing a valid data collection instruments the researcher:

- Ensured that the conceptual definitions were translated into operational definitions that could be measured and quantified to enable the research instrument (or tool) to measure the intended constructs.

- Carefully considered the information to be collected, and designed the form accordingly in order to comprehensively and accurately measure all aspects of concerned constructs.

- Specified key items for data extraction in advance in a data extraction template, based on the participants, interventions, comparisons and outcomes of interest.

- Collected study aspects that could (or were believed to) affect the presence or magnitude of an intervention effect and those that could help assess applicability.

- Used the collected data to address characteristics of included studies, risk of bias assessment, and statistical analysis.

- Verified the data for accuracy and completeness on data transfer. 


\subsection{CONCLUSION}

This chapter presented an overview of the research design and methods. The next chapter presents analysis and description of the research findings. 


\section{CHAPTER 4}

\section{ANALYSIS, PRESENTATION, AND DESCRIPTION OF THE RESEARCH FINDINGS}

\subsection{INTRODUCTION}

This chapter focuses on the data collection and analysis process and description of the study results. The chapter further addresses the characteristics of included studies and excluded studies, followed by the risk of bias in included studies and the effects of monitoring frequency. The findings are then discussed in line to the research objectives.

\subsection{DESCRIPTION OF STUDIES}

The relevant studies were described in detail under Characteristics of Studies (Annexure D) with the specific titles of "Characteristics of included studies" and "Characteristics of excluded studies".

\subsection{RESULTS OF THE SEARCH}

Results of the search for studies were organized and illustrated using study flow diagram generated in RevMan. The Study flow diagram was used to illustrate the search outcome, and the process of screening and selecting studies for inclusion in this meta-analysis.

\subsubsection{Search outcomes}

From the search strategy (Annexure E), 860 titles were initially identified. After duplicates were removed, 681 citations remained to be screened. An initial single screen of these titles and abstracts, removed all titles which did not fit inclusion criteria, such as editorials, letters, clearly off topic studies. This initial single screening resulted in 668 studies being excluded. The inclusion criteria applied on the remaining 13 studies of which the full articles were obtained. Studies were reviewed for relevance, based on study design, types of participants, exposures, and outcomes measures. Of the 13 potentially relevant studies, eight met the inclusion criteria and were included in the review. The details of how the researcher ultimately excluded and included studies are displayed in the study flow diagram (Figure 4.1). 


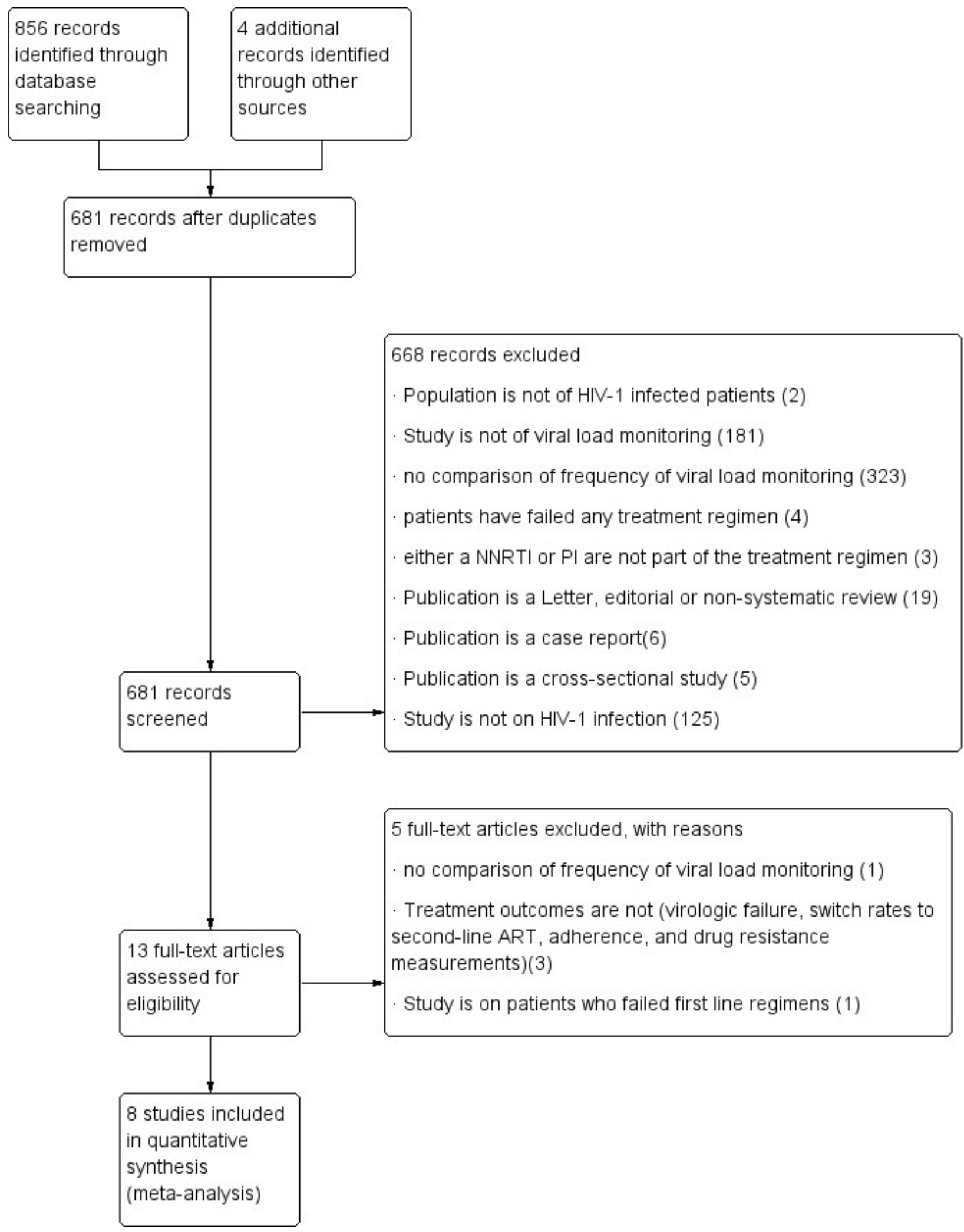

Figure 4. 1 Flow diagram of eligibility criteria of studies

\subsubsection{Search yield}

In total, the researcher identified one randomised trial and seven observational studies with comparators for data extraction, coding, and potential meta-analysis. 


\subsection{INCLUDED STUDIES}

\subsubsection{Randomized trials}

Weissman (2016) presents results from a randomised trial designed to determine the impact of changing scheduled follow up care for persons with HIV from a 4 to 6 months interval. It was conducted at an HIV clinic in South Carolina, USA on randomised patients who were followed for 18 months. A total of 165 patients, median age of 46.8 were randomised to twostudy arms of the standard of care visit every 4 months versus the standard of care visits at 6 months intervals. The primary outcome was virologic failure, which they defined as two successive VLs of $>200$ copies $/ \mathrm{ml}$. Secondary outcomes included the quality of life (QOL), and adherence. The study found no difference in virologic failure after 24 months between monitoring every 4 months versus every 6 months. For stable, HIV VL suppressed population less frequent HIV monitoring was safe during this short follow up. There was also no difference in $\mathrm{QOL}$ or adherence.

\subsubsection{Observational studies with comparators}

Seven observational studies met the inclusion criteria of this study. These studies aimed to evaluate a range of primary outcomes: time to detection of antiretroviral therapy (ART) failure (Bryant. 2012) and percentage of total person-years spent with virological failure (Schneider. 2011), virological failure (Caniglia. 2016;Chaiwarith. 2011; Young. 2015), and treatment failure due to virological failures (Reekie. 2008; Romih. 2010). In resource-constrained settings, two studies were conducted in Thailand (Chaiwarith. 2011; Schneider. 2011), and one in Croatia (Romih. 2010). The other five cohort studies were based on high-income settings. Six studies included adults infected with HIV-1, and one study was based on data from a cohort of children (Schneider. 2011). In one study the comparison groups were plasma HIV-1 RNA monitoring at least thrice yearly versus plasma HIV-1 RNA monitoring twice yearly (Young. 2015). The other six studies were more inclusive, the comparison groups were plasma HIV-1 RNA monitoring at least twice yearly versus plasma HIV-1 RNA monitoring at most Once yearly.

\subsection{EXCLUDED STUDIES}

Five studies were excluded due to their irrelevance to the intervention or outcomes of interest as indicated in the 'Characteristics of excluded studies' table (Annexure D). 


\subsubsection{Randomized trials}

Haubrich et al (2001) presents results from a randomised trial designed to compare frequent measurement with infrequent measurement of human immunodeficiency virus (HIV) RNA levels in the management of antiretroviral therapy. The California Collaborative Treatment Group (CCTG) initiated a randomised clinical study from the primary care practices of 6 university affiliated clinical sites. A group of 206 patients, above 18 years (interquartile range 21 to 64 , median 37) were randomised to two-study arms of the frequent group with $\geq 3$ VLs performed per year versus the infrequent group with $\leq 2$ VLs per year. The primary outcome was the area-based measure of viral suppression, the ACFB in HIV RNA levels. Secondary outcomes included the duration of undetectable virus load levels. The study found that, more frequent HIV RNA monitoring resulted in a reduction in virus load nearly twice than seen with less frequent virus load monitoring. Frequent HIV RNA monitoring resulted in near-doubling of the proportion and the duration of undetectable virus load levels. The study was excluded because it did not require individuals to be virologically suppressed at entry and did not look at treatment outcomes such as virologic failure, switch rates to second-line ART, adherence, and drug resistance measurements.

\subsubsection{Observational studies}

Braithwaite (2014) in an observational study describes the results of how different eligibility guidelines for antiretroviral therapy affect the cost-effectiveness of routine viral load testing. The study was conducted in sub-Saharan Africa, and the primary outcome was the incremental cost-effectiveness ratio (ICER). The study was excluded because it did not look at treatment outcomes such as virologic failure, switch rates to second-line ART, adherence, and drug resistance measurements.

In Canada, Raboud (2010) conducted a study on regional differences in rates of HIV-1 viral load monitoring and their implications on antiretroviral care in high income countries. The primary outcome was the frequency of $V L$ testing. The study was excluded because the outcome of interest is the frequency of VL monitoring, instead of clinical/health outcomes due to variations in frequency of $\mathrm{VL}$ testing.

Rossouw (2017) conducted an observational study with comparators on patients who had failed a first-line NNRTI-based HAART regimen. The study was conducted in an urban and a rural setting in South Africa and the primary outcome was HIV-associated drug resistance 
(HIVDR). It was excluded because all patients had failed a first-line NNRTI-based HAART regimen.

Thirunavukarasu (2016) in a study conducted in South India reports on the patterns of HIV-1 drug-resistance mutations among patients failing first-line antiretroviral treatment. The outcome of interest was HIV-associated drug resistance. The study was excluded because it does not evaluate the frequency of viral load monitoring after initiation of ART; instead it evaluates the frequency and patterns of HIV-1 drug-resistance mutations.

\subsection{RISK OF BIAS IN INCLUDED STUDIES}

An assessment of the validity of studies included in this study emphasized the risk of bias in their results. The risk of bias was specifically assessed for both RCTs and observational studies. Risk of bias tables were generated, with support for the judgement on each entry addressing a specific feature of the study. Detailed considerations for the assessment of these features are provided below.

\subsubsection{Randomised Control Trials}

The following apply to the one included randomised trial. Summaries of the assessment of the 'Risk of bias' are depicted in Figure 4.2 and Figure 4.3.

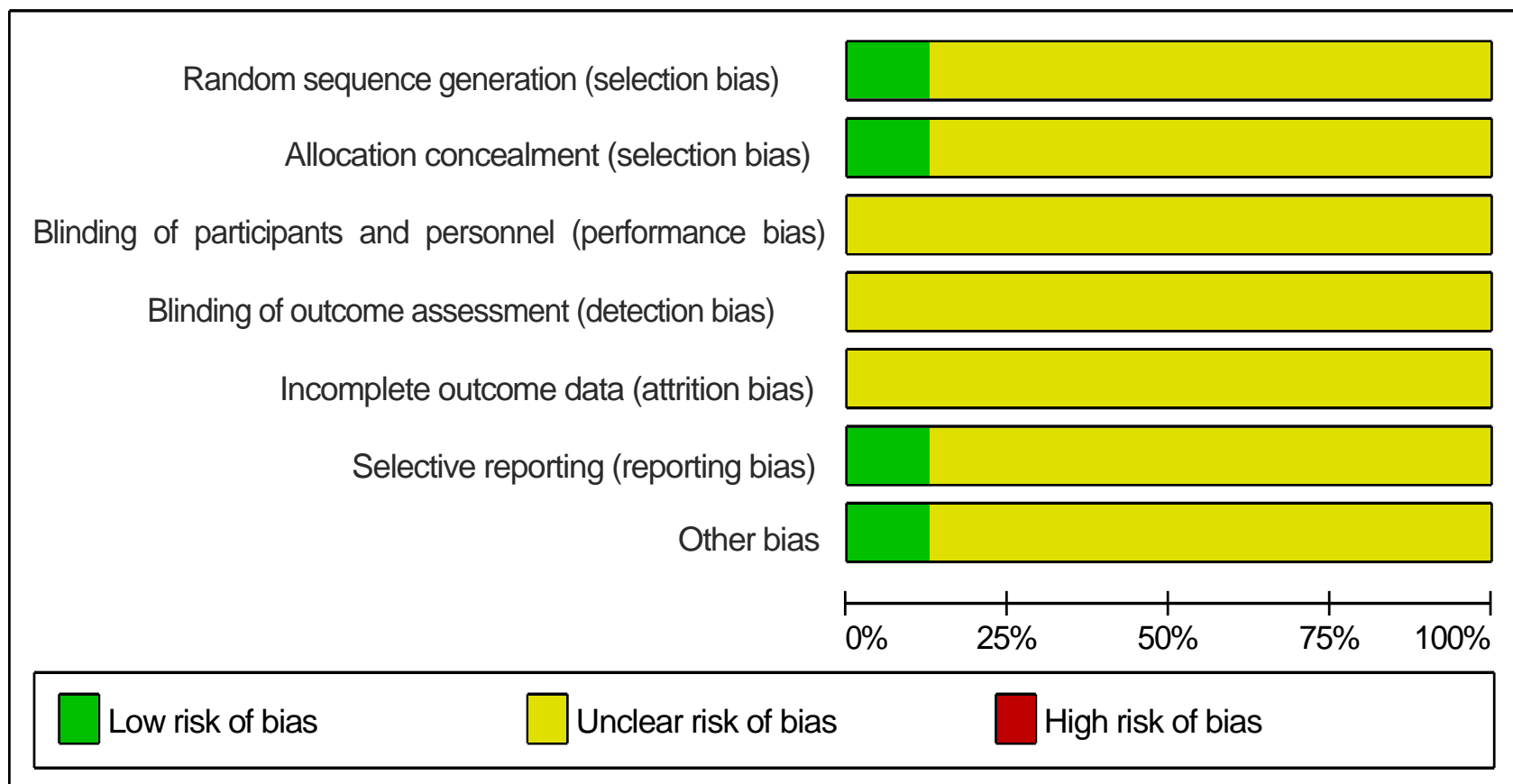

Figure 4. 2 Risk of bias graph: review researcher's judgements about each risk of bias item presented as percentages across all included studies. 


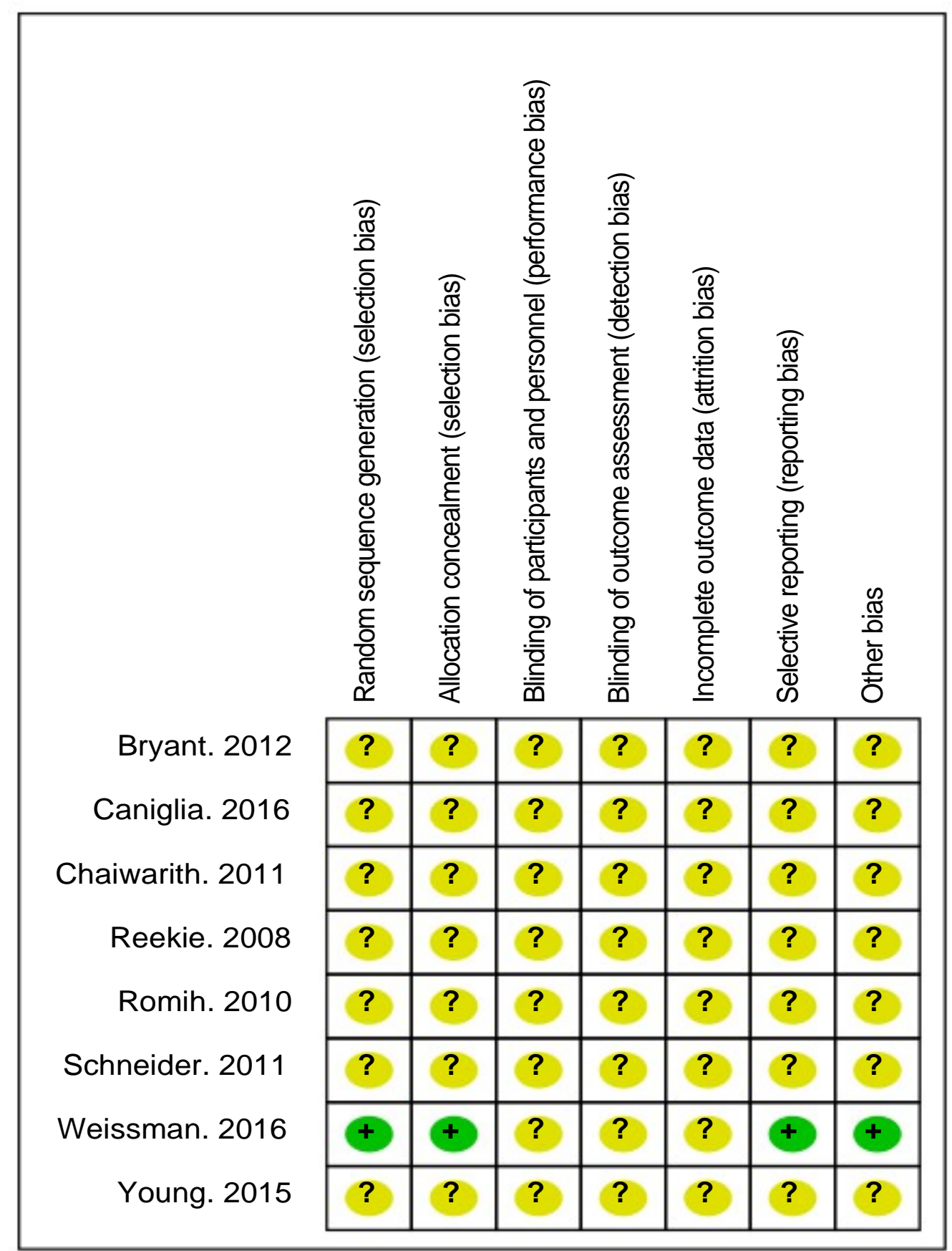

Figure 4. 3 Risk of bias summary: review authors' judgements about each risk of bias item for each included study.

- Allocation (selection bias)

Generation of the allocation sequence and concealment of allocation was adequately performed in the trial (Weissman. 2016), and patients infected with HIV were randomized into 1 of 2 groups, that is, every 4 months monitoring (Group I) or 6 month monitoring (Group II). Baseline characteristics did not differ between the groups. The Weissman (2016) trial did describe details of allocation concealment. No systematic differences between groups in the care that was provided, and the standard care included: medical provider visits and 
laboratory monitoring, which included CD4 county and VL among others.

- Blinding (performance bias and detection bias)

No information was available for Weissman (2016) on blinding. It is unclear if either the outcome assessors or patient participants were blinded. Non-blinding was not likely to introduce bias.

- Incomplete outcome data (attrition bias)

No information was available for Weissman (2016) on incomplete outcome data due to loss to follow-up.

- Selective reporting (reporting bias)

The trial by Weissman (2016) appeared to be free of selective reporting. The outcomes mentioned in the methods sections were reported in the results sections.

- Other potential sources of bias

The trial by Weissman (2016) appeared to be free of other potential sources of bias, and there are no clear sources for other potential bias.

\subsubsection{Observational studies}

Seven observational studies (Bryant. 2012; Caniglia. 2016; Chaiwarith. 2011; Reekie. 2008; Romih. 2010; Schneider. 2011; Young. 2015) were included in the final analysis of observational studies characteristics and methodological quality as shown in Table 4.1. 
Table 4. 1 Newcastle-Ottawa quality assessment scale for included observational studies

\begin{tabular}{|l||l||l|l|l|l|l|l|}
\hline ITEM & $\begin{array}{l}\text { Bryant. } \\
\mathbf{2 0 1 2}\end{array}$ & $\begin{array}{l}\text { Schneider. } \\
\mathbf{2 0 1 1}\end{array}$ & $\begin{array}{l}\text { Chaiwarith. } \\
2011\end{array}$ & $\begin{array}{l}\text { Romih. } \\
\mathbf{2 0 1 0}\end{array}$ & $\begin{array}{l}\text { Reekie. } \\
2008\end{array}$ & $\begin{array}{l}\text { Caniglia. } \\
2016\end{array}$ & $\begin{array}{l}\text { Young. } \\
2015\end{array}$ \\
\hline $\begin{array}{l}\text { Representativeness of } \\
\text { Cohort }\end{array}$ & 1 & 1 & 1 & 1 & 1 & 1 & 0 \\
\hline $\begin{array}{l}\text { Selection of Non-exposed } \\
\text { Cohort }\end{array}$ & 0 & 1 & 0 & 1 & 0 & 1 & 1 \\
\hline Ascertainment of Cohort & 0 & 1 & 0 & 0 & 1 & 0 & 1 \\
\hline $\begin{array}{l}\text { Outcome of Interest Not } \\
\text { Present at Start of Study }\end{array}$ & 1 & 1 & 0 & 1 & 1 & 0 & 0 \\
\hline Comparability of Cohorts 1 & 1 & 1 & 0 & 1 & 1 & 1 & 1 \\
\hline Comparability of Cohorts 2 & 1 & 1 & 0 & 1 & 0 & 1 & 1 \\
\hline Assessment of Outcome & 1 & 0 & 0 & 1 & 1 & 1 & 1 \\
\hline Long Enough Follow-up & 1 & 1 & 0 & 1 & 0 & 1 & 1 \\
\hline Adequacy of Follow-up & 1 & 1 & 0 & 0 & 0 & 0 & 1 \\
\hline TOTAL & $\mathbf{7}$ & $\mathbf{8}$ & $\mathbf{1}$ & $\mathbf{7}$ & $\mathbf{5}$ & $\mathbf{6}$ & $\mathbf{7}$ \\
\hline
\end{tabular}

\subsection{EFFECTS OF INTERVENTIONS}

All eight studies evaluated the effects of different frequencies of VL monitoring on virological outcomes (Caniglia 2016; Chaiwarith 2011; Reekie 2008; Romih 2010; Weissman 2016) reported the virological outcome as Virological failure. The cut-off for viral load suppression was reported at different levels in each of the studies with (Caniglia 2016; Young 2015) considering virologic failure as HIV RNA $\geq 200$ copies/mL, and in Weissman (2016) virologic failure was defined as two successive VLs of $\geq 200$ copies $/ \mathrm{ml}$. Of the evidence available, two comparisons were studied; namely, frequent testers of $\geq 3$ VLs per year versus less frequent testers of $\leq 2$ VLs per year; and frequent testers of $\geq 2$ VLs per year versus less frequent testers of $\leq 1$ VLs per year. 


\subsubsection{Comparison 1: Frequent testers ( $\geq 3$ vls per year) versus less frequent testers ( $\leq 2$ vls per year)}

Based upon five studies including 10,695 patients, the risk of VL failure in the $\geq 3$ VLs per year monitoring strategy is not different at all when compared with the risk of VL failure in a less frequent ( $\leq 2$ VLs per year) monitoring strategy ( $R R 1.00,95 \% \mathrm{Cl} 0.80$ to 1.25 ). Significant statistical heterogeneity was found for the outcome of VL failure (I2=84\%, $\mathrm{p}=0.0001$ ) as shown in Figure 4.4 (Analysis 1.1). Only one trial reported on adherence (Weissman. 2016). This study found no difference in adherence scores of the two study arms, (SMD 0.00, 95\% Cl -0.33 to 0.33) as shown in Figure 4.5 (Analysis 1.2).

\subsubsection{Comparison 2: Frequent testers ( $\geq 2$ VLs per year) versus less frequent testers ( $\leq 1 \mathrm{VLs}$ per year)}

Based upon four studies including 6,329 patients, $\geq 2$ VLs per year monitoring the results in reduced VL failure, compared with less frequent monitoring of $\leq 1$ VLs per year, and RR 1.82, $95 \% \mathrm{Cl} 1.43$ to 2.30 as shown in Figure 4.6 (Analysis 2.1). The $\geq 2$ VLs per year monitoring led to a reduction in percentage of total person-years spent with virological failure (data from Schneider 2011 only). (MD 32.00, 95\% Cl 13.97 to 50.03) as shown in Figure 4.7 (Analysis 2.2). The $\geq 2$ VLs per year monitoring results in reduction of the time for the detection of virologic failure (data from Bryant 2012 only, (MD 0.80, 95\% Cl 0.69 to 0.91) as shown in Figure 4.8 (Analysis 2.3). 


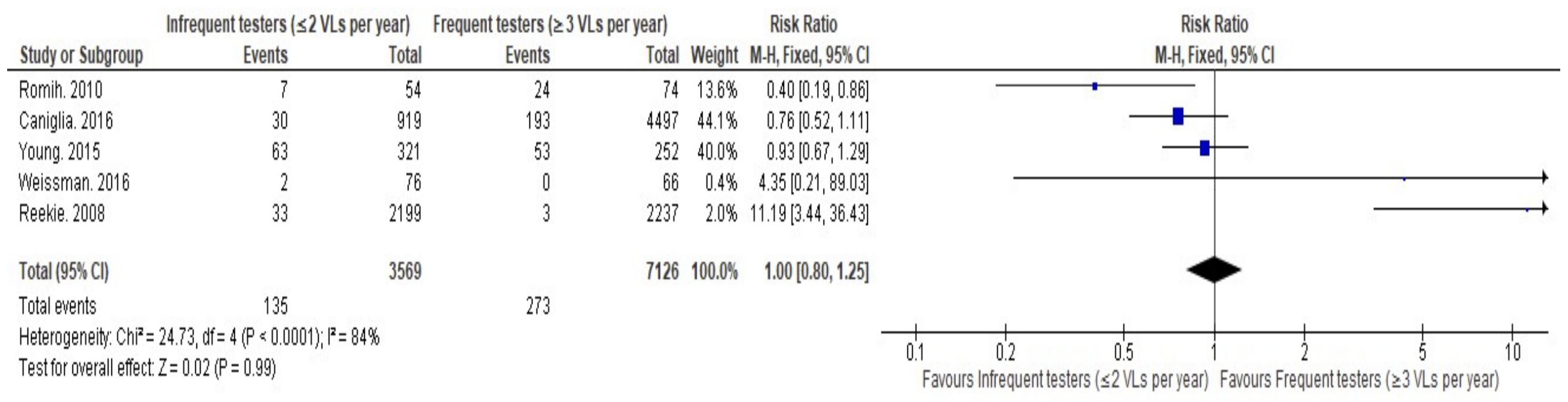

Figure 4. 4 (Analysis 1.1) Forest plot of comparison: 1 Frequent monitoring ( $\geq 3$ VLs per year) versus less frequent monitoring ( $\leq 2$ VLs per year), outcome: 1.1 Virologic failure.

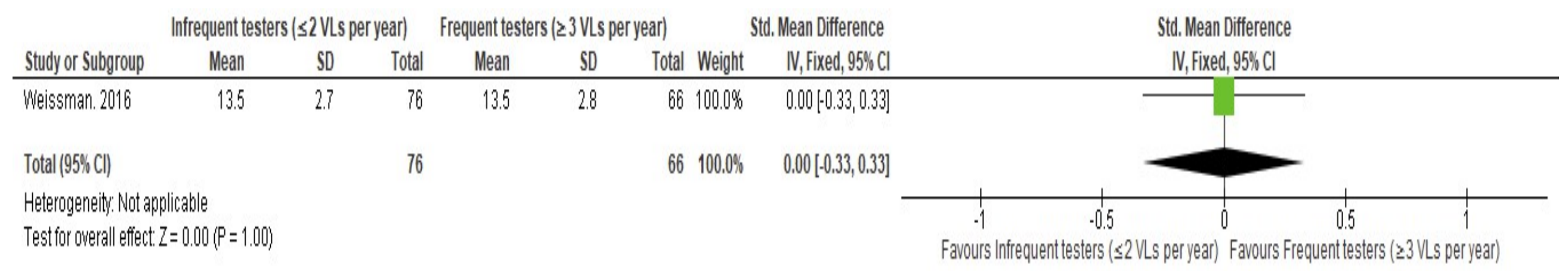

Figure 4. 5 (Analysis 1.2) Forest plot of comparison: 1 Frequent monitoring ( $\geq 3$ VLs per year) versus less frequent monitoring ( $\leq 2$ VLs per year), outcome: 1.2 Adherence scores. 


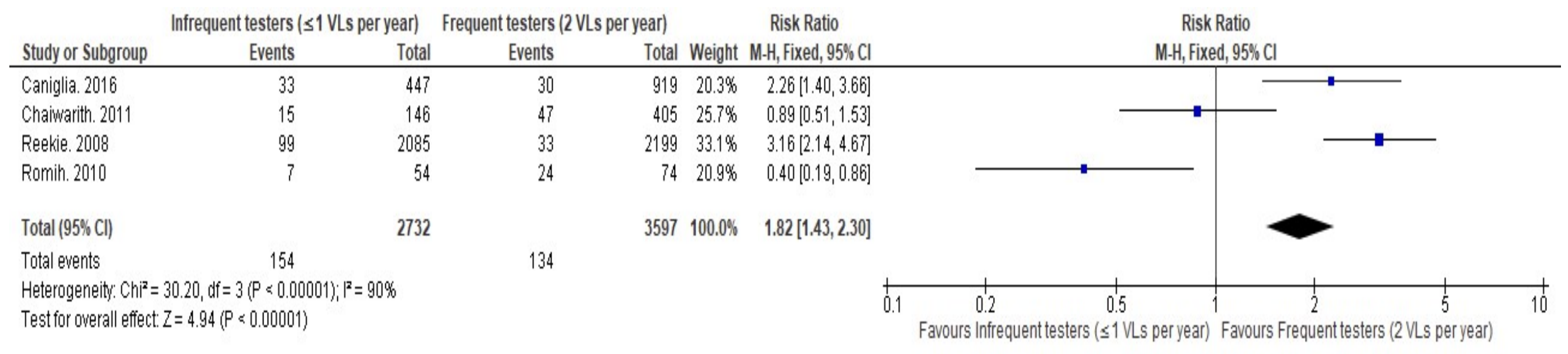

Figure 4. 6 (Analysis 2.1) Forest plot of comparison: 2 Frequent monitoring (2 VLs per year) versus less frequent monitoring ( $\leq 1$ VLs per year), outcome: 2.1 Virologic failure.

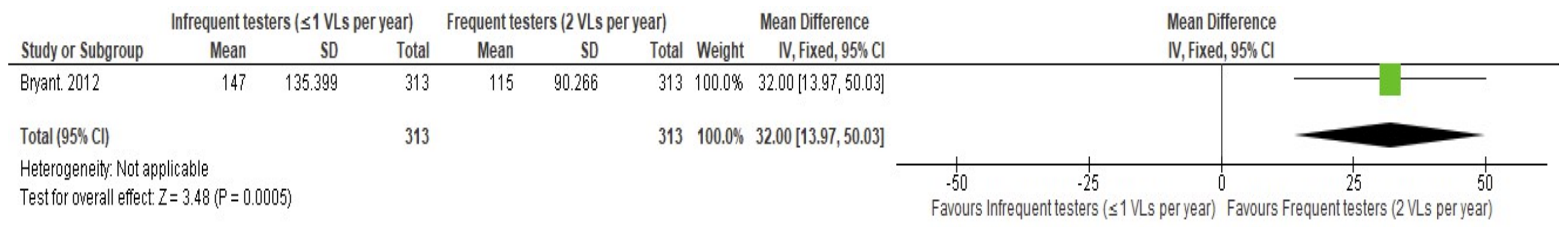

Figure 4. 7 (Analysis 2.2) Forest plot of comparison: 2 Frequent monitoring (2 VLs per year) versus less frequent monitoring ( $\leq 1$ VLs per year), outcome: 2.2 median time for the detection of virologic failure. 


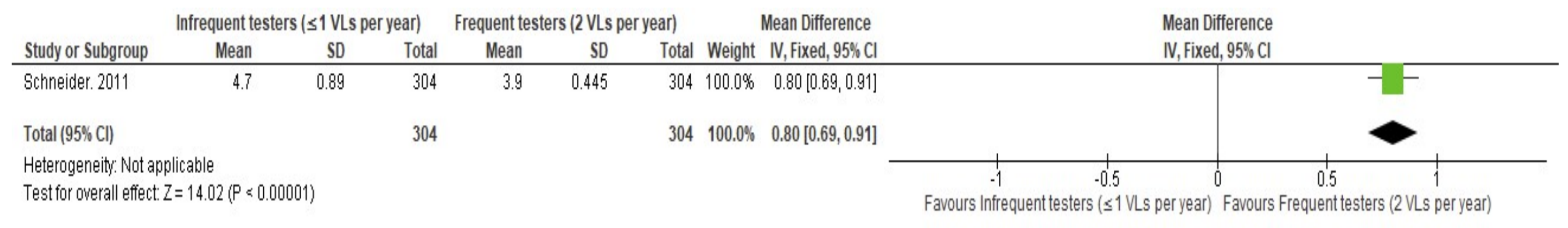

Figure 4. 8 (Analysis 2.3) Forest plot of comparison: 2 Frequent monitoring (2 VLs per year) versus less frequent monitoring ( $\leq 1$ VLs per year), outcome: 2.3 Percentage of total person-years spent with virological failure. 


\subsection{DATA AND ANALYSIS TABLES}

Table 4. 2 Frequent monitoring ( $\geq 3$ VLs per year) versus less frequent monitoring ( $\leq 2$ VLs per year)

\begin{tabular}{|c|c|c|c|c|}
\hline Outcome or Subgroup & Studies & Participants & Statistical Method & Effect Estimate \\
\hline 1.1 Virologic failure & 5 & 10695 & Risk Ratio (M-H, Fixed, 95\% Cl) & $1.00[0.80,1.25]$ \\
\hline 1.2 Adherence scores & 1 & 142 & Std. Mean Difference (IV, Fixed, 95\% Cl) & $0.00[-0.33,0.33]$ \\
\hline
\end{tabular}

Table 4. 3 Frequent monitoring ( 2 VLs per year) versus less frequent monitoring ( $\leq 1$ VLs per year)

\begin{tabular}{|c|c|c|c|c|}
\hline Outcome or Subgroup & Studies & Participants & Statistical Method & Effect Estimate \\
\hline 2.1 Virologic failure & 4 & 6329 & Risk Ratio (M-H, Fixed, 95\% Cl) & $1.82[1.43,2.30]$ \\
\hline 2.2 median time for the detection of virologic failure & 1 & 626 & Mean Difference (IV, Fixed, 95\% CI) & $32.00[13.97,50.03]$ \\
\hline $\begin{array}{l}\text { 2.3 Percentage of total person-years spent with } \\
\text { virological failure }\end{array}$ & 1 & 608 & Mean Difference (IV, Fixed, 95\% CI) & $0.80[0.69,0.91]$ \\
\hline
\end{tabular}




\subsection{CONCLUSION}

In this chapter data were collected from eight studies and analysed using meta-analysis method. Two comparison groups emerged from the study being; frequent monitoring ( $\geq 3 \mathrm{VLS}$ per year) versus less frequent monitoring ( $\leq 2 \mathrm{VLs}$ per year) and frequent monitoring ( $2 \mathrm{VLs}$ per year) versus less frequent monitoring ( $\leq 1 \mathrm{VLs}$ per year). The next chapter presents the conclusion and recommendations. 


\section{CHAPTER 5}

\section{CONCLUSIONS AND RECOMMENDATIONS}

\subsection{INTRODUCTION}

The objective of this chapter is to provide the summary of the findings, applicability of evidence, recommendations for practice and research.

\subsection{SUMMARY OF MAIN RESULTS}

Despite a comprehensive search, a limited number of studies were identified which addressed this topic, and, of the one randomised trial identified, evaluated the primary outcome of interest, virologic failure. Observational studies were also limited in number and they were of good quality. Of the seven observational studies identified, one was in abstract form only when the literature search was conducted. There appeared to be substantial value to clinical care for key outcomes; namely, virological failure and median time for the detection of virologic failure favouring a monitoring strategy with frequency of 2 VLs per year versus either $\geq 3$ VLs per year or $\leq 1$ VLs per year. Evidence from the seven observational studies and one randomised trial found no difference in virologic failure between the frequent monitoring of $\geq 3$ VLs per year and the less frequent monitoring of 2 VLs per year. Therefore, in this study, VL monitoring in adherent patients with a stable undetectable VL can be reasonably extended from 3 months to every 6 months. The findings from the observational studies alone suggest that a monitoring strategy of $\leq 1 \mathrm{VLs}$ per year increases the risk of virologic failure compared with monitoring every 6 months. Most of the included studies did not report on adherence, however, there is no indication that frequent monitoring would improve patient adherence.

In Weissman (2016) a randomised trial that evaluated virologic failure, there were no differences seen in the risk of virologic failure when comparing $\geq 3$ VLs per year and 2 VLs per year. While 2 VLs per year monitoring strategy appears to have benefits in early detection of virological failure and reducing the risk of failure compared to $\leq 1$ VLs per year monitoring strategy, there remain many areas of uncertainty. For example, there remains no standardised definition for VL failure in the included studies. In Caniglia (2016) and Young (2015) virologic failure was defined as HIV RNA $\geq 200$ copies/mL, in contrast to the study by 
Weissman (2016) where virologic failure was defined as two successive VLs of $\geq 200$ copies/ml.

Further complicating the standard of VL failure is that in Bryant (2012) virologic failure was defined as HIV-1 RNA > 400 copies/mL, after previously having achieved viral suppression. In Schneider (2011) virologic failure was defined as increased plasma HIV RNA to at least 1000 RNA copies/ml after having previously undetectable viral load. Due to the different standards of VL failure, the estimates of effect from Bryant (2012) and Schneider (2011) could not be combined into a summary estimate as their patients are not virologically suppressed based on the standards of the other studies (Caniglia 2016; Young 2015; Weissman 2016).

The benefit of the 2 VLs per year monitoring strategy must also be considered in the context of its associated costs. Most of the included studies relied on clinical cohorts based on highincome countries and thus these data may indirectly or partially generalizable to resourcelimited settings. In this study, the researcher did not assess the costs that may be associated with the different monitoring frequencies. One of the included observational studies (Bryant 2012) compared the cost of Frequent testing of $\geq 2$ VLs per year versus less frequent testing of $\leq 1$ VLs per year; and found that the cost of reduced monitoring scheme of $\leq 1$ VLs per year would be significantly less than the 2 VLs per year monitoring scheme. The 2 VLs per year monitoring resulted in the reduction of the time to detect virologic failure when compared with the reduced monitoring scheme of $\leq 1$ VLs per year.

While a statistically significant difference was shown; it was not necessarily clinically significant (Bryant et al 2013:3). In low-income settings where monitoring ART is based on CD4 counts only, using a reduced monitoring scheme can add value to clinical care with minimal added costs. Monitoring of viral loads in low-income settings with a reduced sampling scheme such as the one in Bryant (2012), where VLs are performed at certain interval like 6,36 , and 60 months, is a promising variant of virologic monitoring in need of further evaluation in a randomised control study. In such a randomised trial, patients would be randomised to receive standard viral load testing every 6 months or to one or more reduced viral load-monitoring schemes. The aim would be to monitor subjects for virological failure and determine whether the use of a reduced sampling scheme in low-income settings would be equally effective at a lower cost than standard testing. The primary outcome, virologic failure, would be measured between the groups. 
This study findings support the current WHO recommendations for biannual VL monitoring among clinically stable and virologically suppressed HIV-infected patients. VL monitoring at 2 VLs per year monitoring frequency was not associated with increased rates of virologic failure and could generate substantial financial cost savings without jeopardizing patient safety, freeing the resources to expand, and improve other aspects of HIV care.

\subsection{OVERALL COMPLETENESS AND APPLICABILITY OF EVIDENCE}

The eight studies included, evaluate effects of different monitoring frequencies used to monitor virologically suppressed patients, which limits the researcher's ability to make broad generalizations on patients who are not necessarily suppressed. A trial by Haubrich et al (2001:6), that did not require individuals to be virologically suppressed at entry, had a study population predominately with a low CD4 cell count and had HIV-1 RNA levels of $\geq 5000$ copies/mL. the study found that frequent monitoring of HIV RNA levels, perhaps as often as every 2 months, may be necessary to detect loss of virological suppression and adjust therapy accordingly (Haubrich et al 2001:7).

\subsection{QUALITY OF THE EVIDENCE}

The overall quality of evidence in the eight studies included in this meta-analysis is moderate, as described earlier in section 4.6 for the "RISK OF BIAS IN INCLUDED STUDIES". Only one was a randomised controlled trial and the other seven were observational studies and therefore introduced selection bias. The randomised study had a small sample size and a relatively short follow up time. While the findings are interesting and informative, it is important to note that they are reliant on observational studies and one small randomised trial. The utilization of data published in observational studies may not represent the full picture on causality. The primary reason for downgrading the quality of evidence was 'indirectness', the researcher had only one trial to make broad generalizations about the potential effects. Publication bias was minimized by a comprehensive search strategy that included evaluating published and unpublished literature. 


\subsection{AGREEMENTS AND DISAGREEMENTS WITH OTHER STUDIES OR REVIEWS}

There is one randomised clinical trial (Haubrich et al 2001:7) comparing frequent measurement with infrequent measurement of human immunodeficiency virus (HIV) RNA levels in the management of antiretroviral therapy. A closer inspection of this trial indicates that it did not require individuals to be virologically suppressed at entry. This trial was not included in this meta-analysis because its eligibility criteria on the types of participants and outcome measures were inconsistent with the included studies. The failure of the studies included in this meta-analysis to find a benefit of $\geq 3$ VLs per year versus 2 VLs per year)monitoring is in disagreement with the findings of this excluded trial (Haubrich et al 2001:7). With an exception of Haubrich et al (2001), there are no other studies or systematic reviews addressing this topic that the researcher is aware of at this time.

\subsection{CONCLUSIONS}

\subsubsection{Recommendations for practice}

Evidence in this meta-analysis supports the use of 2 VLs per year as the optimal monitoring strategy for stable, HIV VL suppressed adult population and there is nothing to be gained by a more frequent monitoring of $\geq 3$ VLs per year. However, further costanalysis studies are necessary to solidify these findings and make conclusions about the long term applicability of this strategy to low-resource settings. It is not known whether the use of 2 VLs per year monitoring strategy on patients who are not virologically suppressed and unstable, could be safe for patients. More research should be conducted on similar interventions to address patients who are not virologically suppressed, in resource constrained countries, and be inclusive of children.

\subsubsection{Recommendations for research}

Only one trial evaluated the effects of different monitoring frequencies on virologic response. The trial was conducted in developed countries, in adult population, and all included patients had sustained virologic suppression. The "Test and Teat" strategy will include patients, regardless of CD4 and viral load status, and subsequently having healthy individuals being enrolled for ART. Therefore monitoring frequency reduction studies in healthy, HIV positive patients may be warranted if "Test and Treat" strategy is universally 
rolled-out. Randomized controlled trials investigating the efficacy and safety of $\leq 1$ VLs per year in ART patients enrolled through the "Test and Treat" strategy are needed. Given the evidence that $\leq 1$ VLs per year may be unsafe for patients, it is unlikely that a clinical trial for such a monitoring frequency would be acceptable to some researchers and people affected by HIV. Therefore such a trial will require much innovation including education of people affected by HIV.

\subsection{CONTRIBUTIONS OF THE STUDY}

These study findings contribute to the body of knowledge to better understand optimal virologic monitoring frequencies for HIV-1 infected individuals. Furthermore, the findings contribute towards evidence-based medical decisions with regards to optimal frequency of viral load monitoring. As a way of dissemination of information, the researcher will present the study at conferences to report and share the research finding with other researchers and concerned communities at large. The study findings will also be published in the relevant academic journals to increase the dissemination of the body of knowledge.

\subsection{LIMITATIONS OF THE STUDY}

The findings of this meta-analysis favour a virologic monitoring frequency of every 6 months; however, they are highly reliant on a single trial and seven observational studies. It is necessary to have further trials from other settings evaluating VL failure as a primary outcome of different monitoring frequencies and a standardised virologic failure defined as HIV-1 RNA $\geq 400$ copies/mL after previously having achieved viral suppression. To validate the findings of this meta-analysis, larger RCTs with longer follow up time should be conducted. Two of the studies (Bryant. 2012; Schneider. 2011) assessed different outcomes and did not assess VL failure. Because of heterogeneity in the types of outcomes, the researcher was unable to pool data from the two studies for meta-analysis. There is a need to introduce an affordable, feasible and sustainable system for viral load monitoring in resource limited contexts aimed at all patients including disadvantaged group. It is also important to note that the included trial (Weissman. 2016) did not include children, and only one observational study (Schneider. 2011) included children but did not evaluate the VL failure as an outcome. Children could therefore be an important group for further research. The sample size was relatively small. 


\subsection{CONCLUDING REMARKS}

In conclusion, several studies evaluating the effects of different VL monitoring frequencies on viorologic response have been conducted to date. The differences in their results are largely due to differences in their definition of Virologic failure, and what they consider frequent or infrequent monitoring. Only by standardising and controlling for these can the effects of VL monitoring be studied in detail. Therefore, there is need to adopt standardised cut off points for virologic failure. Overall, this meta-analysis supports the use of 2 VLs per year as the optimal monitoring strategy for stable, HIV VL suppressed adult population. 


\section{LIST OF REFERENCES}

A Dictionary of Epidemiology. 2008. Sv "HEALTH INDICATOR". Fifth edition. New York: Oxford University Press, Inc.

A Dictionary of Epidemiology. 2008. Sv "monitoring". Fifth edition. New York: Oxford University Press, Inc.

Alasuutari, P, Bickman, L \& Brannen, J. 2008. Conducting a meta-analysis. The SAGE handbook of social research methods (pp. 536-554). London: SAGE Publications Ltd

Alston, M \& Bowles, W. 2003. Research for social workers: an introduction to methods, 2nd edition. London: Psychology Press.

Babbie, E. 2007. The practice of social research. 11th edition. Belmont, USA: Thomson Wadsworth.

Bendavid E, Young SD, Katzenstei DA, Bayoumi AM, Sanders GD \& Owens DK. 2008. Cost-effectiveness of HIV Monitoring Strategies in Resource-Limited Settings. A Southern African Analysis. Arch Intern Med 168(17): [1-9].

Botswana Ministry of health. 2012. Botswana National HIV \& AIDS treatment 2012 guidelines. Gaborone: Botswana Ministry of health. From: https://aidsfree.usaid.gov/sites/default/files/tx botswana 2012.pdf (accessed 18 August 2016).

Botswana Ministry of health. 2016. Handbook of the Botswana 2016 integrated HIV clinical care guidelines. Gaborone: Botswana Ministry of health. From:

http://www.moh.gov.bw/Publications/Handbook HIV treatment guidelines.pdf (accessed 18 August 2016).

Bryant, L, Smith, N, \& Keiser, P. 2013. A model for reduced HIV-1 viral load monitoring in resource-limited settings. Journal of the International Association of Providers of AIDS Care 12(1):67-71. 
Caniglia, EC, Sabin, C, Robins, JM, Logan, R, Cain, LE, Abgrall, S, Mugavero, MJ, Hernandez-Diaz, S, Meyer, L, Seng, R \& Drozd, DR. 2016. When to monitor CD4 cell count and HIV RNA to reduce mortality and AIDS-defining illness in virologically suppressed HIVpositive persons on antiretroviral therapy in high-income countries: a prospective observational study. Journal of acquired immune deficiency syndromes 72(2):214-221

Chaiwarith, R, Praparattanapan, J, Nuntachit, N, Kotarathitithum, W, Sirisanthana, T \& Supparatpinyo, K. 2011. Impact of the frequency of plasma HIV-1 RNA monitoring on the outcome of antiretroviral therapy. Current HIV research 9(2):82-87.

Elamin MB, Flynn, DN, Bassler, D, Briel, M, Alonso-Coello, P, Karanicolas, PJ. 2009. Choice of data extraction tools for systematic reviews depends on resources and review complexity. Journal of clinical epidemiology 62(5):[1-6].

ENR see Encyclopedia of Nursing Research:

Encyclopedia of Nursing Research. 2006. Sv "Meta-Analysis". Second Edition. New York: Springer Publishing Company, Inc.

Encyclopedia of public health. 2008. Sv "Disability adjusted life year". Volume 1. New York: Springer Science \& Business Media.

EPH see Encyclopedia of Public Health.

Encyclopedia of public health. 2008. Sv "Population Genetics and Human Health". Volume 1. New York: Springer Science \& Business Media.

ERD see Encyclopedia of Research Design.

Encyclopedia of research design. 2010. Sv "Inclusion criteria'. SAGE Publications, Inc, Thousand Oaks, CA 
Estill J, Egger M, Johnson LF, Gsponer T, Wandeler G, Davies, MA, Boulle, A, Wood, R, Garone, D, Stringer, JS \& Hallett, TB. 2013. Monitoring of antiretroviral therapy and mortality in HIV programmes in Malawi, South Africa and Zambia: mathematical modelling study. PloS one 8(2): [1-8]

Haubrich, RH, Currier, JS, Forthal, DN, Beall, G, Kemper, CA, Johnson, D, Dube, MP, Hwang, J, Leedom, JM, Tilles, J, McCutchan, JA. \& California Collaborative Treatment Group. 2001. A randomized study of the utility of human immunodeficiency virus RNA measurement for the management of antiretroviral therapy. Clinical infectious diseases: an official publication of the Infectious Diseases Society of America 33(7):[1-8].

Keebler D, Revill P, Braithwaite S, Phillips A, Blaser N, Borquez A, Cambiano V, Ciaranello A, Estill J, Gray R, Hill A. 2014. Cost-effectiveness of different strategies to monitor adults on antiretroviral treatment: a combined analysis of three mathematical models. The Lancet Global Health 2(1):([1-8]

Kent DM, McGrath, D, Ioannidis JPA \& Bennish ML. 2003. Suitable Monitoring Approaches to Antiretroviral Therapy in Resource-Poor Settings: Setting the Research Agenda. Clinical Infectious Diseases 37(1): [1-12]

Kerschberger B, Boulle, AM, Kranzer, K, Hilderbrand, K, Schomaker, M, Coetzee, D, Goemaere, E \& Cutsem, GV. 2015. Superior virologic and treatment outcomes when viral load is measured at 3 months compared to 6 months on antiretroviral therapy. Journal of the International AIDS Society 18(20092): [1-7].

Kimberlin, CL, \& Winetrstein, AG. 2008. Validity and reliability of measurement instruments used in research. American Journal of Health-System Pharmacy. 65(23):[1-10]

Moosa, MYH \& Jeenah, FY. 2012. Treating depression in HIV-positive patients affects adherence. Southern African Journal of HIV Medicine 13(3):[1-6]. 
Nieswiadomy, R. M. 2012. Foundations of Nursing Research. Sixth edition. One Lake Street, Upper Saddle River: Pearson Education, Inc.

Paintsil E. 2011. Monitoring Antiretroviral Therapy in HIV-Infected Children in ResourceLimited Countries: A Tale of Two Epidemics, edited by Ann Duerr. AIDS Research and Treatment 2011:280901:[1-9].

Paterson, BL \& Canam, C. 2001. Meta-study of qualitative health research: A practical guide to meta-analysis and meta-synthesis. Nursing in critical care. Sage 8(4), 184-184.

Polit, D.F \& Beck, C.T. 2012. Nursing research: generating and assessing evidence for nursing practice. Ninth edition. Philadelphia: Lippincott Williams \& Wilkins.

Raboud, JM, Loutfy, MR, Su, D, Bayoumi, AM, Klein, MB, Cooper, C, Machouf, N, Rourke, S, Walmsley, S, Rachlis, A, Harrigan, PR, Smieja, M, Tsoukas, C, Montaner, J.S, Hogg, RS \& CANOC Collaboration. 2010. Regional differences in rates of HIV-1 viral load monitoring in Canada: Insights and implications for antiretroviral care in high income countries. BMC infectious diseases 10(1):[1-8]

Rafiee M, Kariminia A, Wright S, Mills G, Woolley I, Smith D, Templeton DJ, Law MG, Petoumenos K. 2014. Reducing viral load measurements to once a year in patients on stable, virologically suppressive cart regimen: Findings from the Australian HIV Observational Database. Journal of AIDS \& clinical research 5(12): [1-6].

Reekie, J, Mocroft, A, Sambatakou, H, Machala, L, Chiesi, A, van Lunzen, J, Clumeck, N, Kirk, O, Gazzard, B, Lundgren, JD \& EuroSIDA Study Group. 2008. Does less frequent routine monitoring of patients on a stable, fully suppressed CART regimen lead to an increased risk of treatment failure? AIDS 22(17):[1-9]

Roberts T, Bygrave H, Fajardo E, Ford N. 2012. Challenges and opportunities for the implementation of virological testing in resource-limited settings. Journal of the International AIDS Society 15(2):[1-7] 
Romih V, Lepej SŽ, Gedike K, Lukas D, Begovac J. 2010. Frequency of HIV-1 viral load monitoring of patients initially successfully treated with combination antiretroviral therapy. PloS one. 5(11):[1-9]

Rossouw, T.M, Nieuwoudt, M, Manasa, J, Malherbe, G, Lessells, RJ, Pillay, S, Danaviah, S, Mahasha, P, van Dyk, G. \& de Oliveira, T. 2017. HIV drug resistance levels in adults failing first-line antiretroviral therapy in an urban and a rural setting in South Africa. HIV medicine 18(2):[1-10]

Schneider, K, Puthanakit, T, Kerr, S, Law, M.G, Cooper, DA, Donovan, B, Phanuphak, N, Sirisanthana, V, Ananworanich, J, Ohata, J \& Wilson, DP. 2011. Economic evaluation of monitoring virologic responses to antiretroviral therapy in HIV-infected children in resourcelimited settings. AIDS (London, England) 25(9): [1-8]

Scott Braithwaite, R, Nucifora, KA, Toohey, C, Kessler, J, Uhler, LM, Mentor, SM, Keebler, D \& Hallett, T. 2014. How do different eligibility guidelines for antiretroviral therapy affect the cost-effectiveness of routine viral load testing in sub-Saharan Africa? AIDS (London, England) 28(1):[1-10]

Thirunavukarasu, D, Udhaya, V, Iqbal, HS. \& Umaarasu, T. 2016. Patterns of HIV-1 DrugResistance Mutations among Patients Failing First-Line Antiretroviral Treatment in South India. Journal of the International Association of Providers of AIDS Care 15(3):[1-7]

Tucker JD, Bien CH, Easterbrook PJ, Doherty MC, Penazzato M, Vitoria M, Peeling RW. Optimal strategies for monitoring response to antiretroviral therapy in HIV-infected adults, adolescents, children and pregnant women: a systematic review. AIDS 28(2):[1-10] 
Weissman, S, Singh, S, Dykema, S. \& Parker, RD. 2016. Randomized controlled trial: 4 month versus 6 month monitoring of HIV-infected patients on highly active antiretroviral therapy. Journal of community health 41(5):[1-7]

WHO.2014. Technical and operational considerations for implementing HIV VIRAL LOAD testing: interim technical update. From: http://www.who.int/hiv/pub/arv/viral-load-testing-technical-update/en/ (accessed 3 July 2016).

World Factbook. 2016. BOTSWANA. From: https://www.cia.gov/library/publications/theworld-factbook/geos/bc.html (accessed 18 August 2016).

Young B, Hart RL, Buchacz K, Scott M, Palella F, Brooks JT. 2015. HIV viral load monitoring frequency and risk of treatment failure among immunologically stable HIV-infected patients prescribed combination antiretroviral therapy. Journal of the International Association of

Providers

of

AIDS

Care

(JIAPAC)

14(6):[1-8] 
ANNEXURE A

\section{ETHICAL CLEARANCE CERTIFICATE}

Approval of research study by the Higher Degrees Committee of the Department of Health Studies 


\section{UNISA $\cong$}

\section{RESEARCH ETHICS COMMITTEE: DEPARTMENT OF HEALTH STUDIES \\ REC-012714-039 (NHERC)}

1 March 2017

Dear Mr Zhou TM

Decision: Ethics Approval

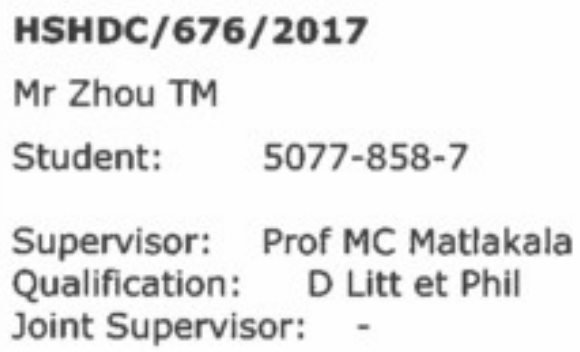

Name: Mr Zhou TM

Proposal: Evaluation of virologic monitoring frequencies on responses to antriretroviral therapy in HIV-1 infected patients.

Qualification: MPCHS94

Thank you for the application for research ethics approval from the Research Ethics Committee: Department of Health Studies, for the above mentioned research. Final approval is granted for the duration of the research period as indicated in your application.

The application was reviewed in compliance with the Unisa Policy on Research Ethics by the Research Ethics Committee: Department of Health Studies on 1 March 2017.

The proposed research may now commence with the proviso that:

1) The researcher/s will ensure that the research project adheres to the values and principles expressed in the UNISA Policy on Research Ethics.

2) Any adverse circumstance arising in the undertaking of the research project that is relevant to the ethicality of the study, as well as changes in the methodology, should be communicated in writing to the Research Ethics Review Committee. Department of Health Studies. An amended application could be requested if there are substantial changes from the existing proposal, especially if those changes affect any of the study-related risks for the research participants. 
3) The researcher will ensure that the research project adheres to any applicable national legislation, professional codes of conduct, institutional guidelines and scientific standards relevant to the specific field of study.

4) [Stipulate any reporting requirements if applicable].

Note:

The reference numbers [top middle and right corner of this communiqué] should be clearly indicated on all forms of communication [e.g. Webmail, E-mail messages, letters] with the intended research participants, as well as with the Research Ethics Committee: Department of Health Studies.

Kind regards,

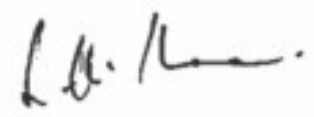

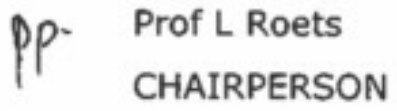

roetsl@unisa.ac.za

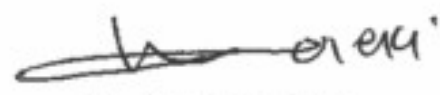

Prof MM Moleki

ACADEMIC CHAIRPERSON

molekmm@unisa.ac.zą 


\section{ANNEXURE B}

STUDY ELIGIBILITY SCREENING FORM 


\begin{tabular}{|c|c|c|c|c|c|}
\hline \multirow{2}{*}{$\begin{array}{l}\text { Study } \\
\text { Characteristics }\end{array}$} & \multirow[t]{2}{*}{ Eligibility criteria } & \multicolumn{3}{|c|}{ Eligibility criteria met? } & \multirow{2}{*}{$\begin{array}{l}\text { Decision } \\
\text { (INCLUDE } \\
\text { or } \\
\text { EXCLUDE)) }\end{array}$} \\
\hline & & Yes & No & Unclear & \\
\hline $\begin{array}{l}\text { Language of } \\
\text { study }\end{array}$ & English & & $\square$ & $\square$ & $\begin{array}{l}\text { INCLUDE if } \\
\text { it's YES only }\end{array}$ \\
\hline \multirow[t]{4}{*}{ Type of study } & Randomised Controlled Trial & $\square$ & $\square$ & $\square$ & INCLUDE \\
\hline & $\begin{array}{l}\text { Quasi-randomised Controlled } \\
\text { Trial }\end{array}$ & $\square$ & $\square$ & $\square$ & INCLUDE \\
\hline & Other design (specify): & $\square$ & $\square$ & $\square$ & INCLUDE \\
\hline & $\begin{array}{l}\text { Letter, editorial, non-systematic } \\
\text { review, observational studies } \\
\text { without comparators, case } \\
\text { report, cross-sectional study } \\
\text { design, or descriptive studies }\end{array}$ & $\square$ & $\square$ & $\square$ & $\begin{array}{l}\text { INCLUDE if } \\
\text { it's NO only }\end{array}$ \\
\hline \multirow[t]{3}{*}{ Participants } & $\begin{array}{l}\text { Populations include ARV-naive, } \\
\text { ARV-experienced or a } \\
\text { combination of these without } \\
\text { restriction on age, ethnicity, } \\
\text { race, and nationality. }\end{array}$ & $\square$ & $\square$ & $\square$ & $\begin{array}{l}\text { INCLUDE if } \\
\text { it's YES only }\end{array}$ \\
\hline & $\begin{array}{l}\text { Population of HIV-1 infected } \\
\text { patients that were initially } \\
\text { virologically well suppressed, } \\
\text { on ART }\end{array}$ & $\square$ & $\square$ & $\square$ & $\begin{array}{l}\text { INCLUDE if } \\
\text { it's YES only }\end{array}$ \\
\hline & $\begin{array}{l}\text { Studies evaluating ART in } \\
\text { patients who have not failed } \\
\text { any treatment regimen }\end{array}$ & $\square$ & $\square$ & $\square$ & $\begin{array}{l}\text { INCLUDE if } \\
\text { it's YES only }\end{array}$ \\
\hline $\begin{array}{l}\text { Types of } \\
\text { intervention }\end{array}$ & $\begin{array}{l}\text { Study must evaluate the } \\
\text { frequency of viral load } \\
\text { monitoring after initiation of } \\
\text { ART }\end{array}$ & $\square$ & $\square$ & $\square$ & $\begin{array}{l}\text { INCLUDE if } \\
\text { it's YES only }\end{array}$ \\
\hline $\begin{array}{l}\text { Types of } \\
\text { comparison }\end{array}$ & $\begin{array}{l}\text { Less frequent ( } \leq 2 \text { VLs per year) } \\
\text { versus more frequent }(\geq 3 \text { VLs } \\
\text { per year) virologic monitoring }\end{array}$ & $\square$ & $\square$ & $\square$ & $\begin{array}{l}\text { INCLUDE if } \\
\text { it's YES only }\end{array}$ \\
\hline
\end{tabular}




\begin{tabular}{|c|c|c|c|c|}
\hline $\begin{array}{l}\text { Types of } \\
\text { outcome } \\
\text { measures }\end{array}$ & $\begin{array}{l}\text { Study should have treatment } \\
\text { outcomes such as virologic } \\
\text { failure, switch rates to second- } \\
\text { line ART, adherence, and drug } \\
\text { resistance measurements }\end{array}$ & $\square$ & $\square \square$ & $\begin{array}{l}\text { INCLUDE if } \\
\text { it's YES only }\end{array}$ \\
\hline & $\begin{array}{l}\text { Studies evaluating switching } \\
\text { ART due to clinical, } \\
\text { immunologic, or virologic failure } \\
\text { rather than substituting ART } \\
\text { due to toxicities }\end{array}$ & & $\square \square$ & $\begin{array}{l}\text { INCLUDE if } \\
\text { it's YES only }\end{array}$ \\
\hline \begin{tabular}{|l|} 
First-line drug \\
regimen details
\end{tabular} & $\begin{array}{l}\text { ART that must include either a } \\
\text { NNRTI or PI as part of their } \\
\text { treatment regimen. }\end{array}$ & $\square$ & $\square \square$ & $\begin{array}{l}\text { INCLUDE if } \\
\text { it's YES only }\end{array}$ \\
\hline \multicolumn{5}{|l|}{\begin{tabular}{|l|} 
INCLUDE $\square$ \\
\end{tabular}} \\
\hline \multicolumn{5}{|l|}{$\begin{array}{l}\text { Reason for } \\
\text { exclusion }\end{array}$} \\
\hline Notes: & & & & \\
\hline
\end{tabular}

DO NOT PROCEED WITH THE STUDY IF IT'S EXCLUDED 


\section{ANNEXURE C}

\section{DATA COLLECTION FORM}




\begin{tabular}{|l|l|}
\hline Date form completed (dd/mm/yyyy) & \\
\hline Name/ID of Reviewer extracting data & \\
\hline Study title & \\
(title of paper/ abstract/ report that data are extracted from) & \\
\hline $\begin{array}{l}\text { Study ID (surname of first author and year first full report of study } \\
\text { was published)) }\end{array}$ & \\
\hline $\begin{array}{l}\text { Publication type } \\
\text { (e.g. full report, abstract, letter) }\end{array}$ & \\
\hline $\begin{array}{l}\text { Study funding source } \\
\text { (including role of funders) }\end{array}$ & \\
\hline $\begin{array}{l}\text { Possible conflicts of interest } \\
\text { (for study authors) }\end{array}$ & \\
\hline Notes: & \\
\hline
\end{tabular}

Eligibility

\begin{tabular}{|l|l|l|l|}
\hline $\begin{array}{l}\text { Study } \\
\text { Characteristics }\end{array}$ & $\begin{array}{l}\text { Review Inclusion Criteria } \\
\text { (Insert inclusion criteria for each } \\
\text { characteristic as defined in the } \\
\text { Protocol) }\end{array}$ & Yes/ No I Unclear & Location in text \\
(pg \& /fig/table)
\end{tabular}




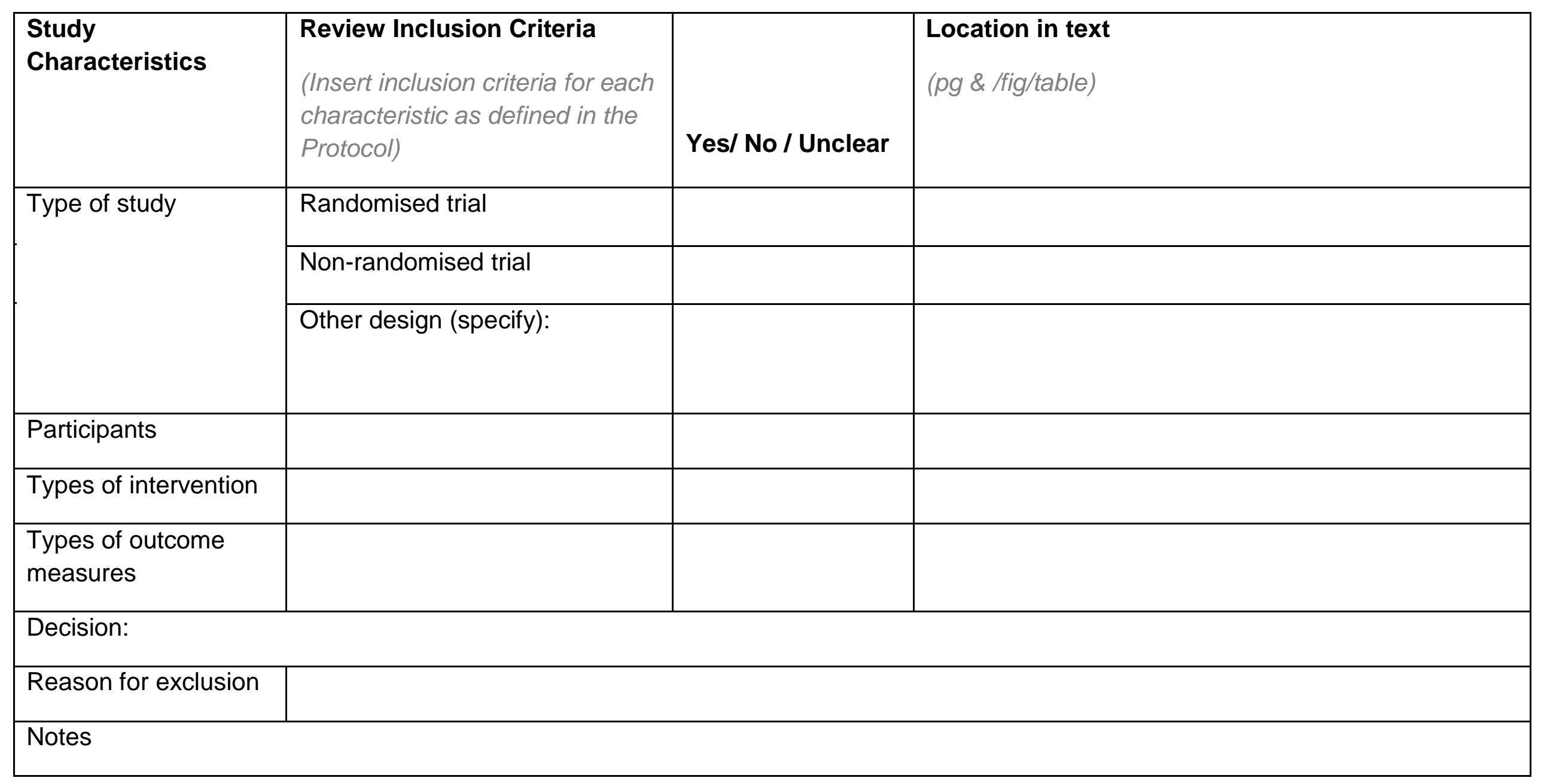

WILL NOT PROCEED IF STUDY IS EXCLUDED FROM REVIEW

Population and setting 


\begin{tabular}{|l|l|l|}
\hline & $\begin{array}{l}\text { Description } \\
\text { Include comparative information for } \\
\text { each group (i.e. intervention and } \\
\text { controls) if available }\end{array}$ & $\begin{array}{l}\text { Location in text } \\
\text { (pg \& /fig/table) }\end{array}$ \\
\hline $\begin{array}{l}\text { Population description } \\
\text { (from which study participants }\end{array}$ & & \\
\hline $\begin{array}{l}\text { Setting } \\
\text { (including location and social } \\
\text { context) }\end{array}$ & & \\
\hline Inclusion criteria & & \\
\hline $\begin{array}{l}\text { Exclusion criteria } \\
\text { participants }\end{array}$ & & \\
\hline
\end{tabular}

Methods

\begin{tabular}{|l|l|l|}
\hline & $\begin{array}{l}\text { Descriptions as stated in } \\
\text { report/paper }\end{array}$ & $\begin{array}{l}\text { Location in text } \\
\text { (pg \& /fig/table })\end{array}$ \\
\hline Aim of study & & \\
\hline
\end{tabular}




\begin{tabular}{|l|l|l|}
\hline $\begin{array}{l}\text { Design } \\
\text { (e.g. parallel, crossover, non- } \\
\text { RCT) }\end{array}$ & & \\
\hline $\begin{array}{l}\text { Unit of allocation } \\
\text { (by individuals, cluster/ groups) }\end{array}$ & & \\
\hline Start date & & \\
\hline End date & & \\
\hline $\begin{array}{l}\text { Duration of participation } \\
\text { (from recruitment to last follow- } \\
\text { up) }\end{array}$ & & \\
\hline Notes: & & \\
\hline
\end{tabular}

Risk of Bias assessment

\begin{tabular}{|l|l|l|l|}
\hline Domain & $\begin{array}{l}\text { Risk of bias } \\
\text { Low/ High/Unclear }\end{array}$ & $\begin{array}{l}\text { Support for } \\
\text { judgement }\end{array}$ \\
\hline $\begin{array}{l}\text { Random sequence generation } \\
\text { (selection bias) }\end{array}$ & $\begin{array}{l}\text { Location in text } \\
\text { (pg \& /fig/tab/e) }\end{array}$ \\
\hline $\begin{array}{l}\text { Other potential threats to } \\
\text { validity (performance bias) }\end{array}$ & & & \\
\hline
\end{tabular}




\begin{tabular}{|l|l|l|l|}
\hline Domain & $\begin{array}{l}\text { Risk of bias } \\
\text { Low/ High/Unclear }\end{array}$ & $\begin{array}{l}\text { Support for } \\
\text { judgement }\end{array}$ & $\begin{array}{l}\text { Location in text } \\
\text { (pg \& /fig/table) }\end{array}$ \\
\hline $\begin{array}{l}\text { Blinding of outcome } \\
\text { assessment } \\
\text { (detection bias) }\end{array}$ & & & \\
\hline $\begin{array}{l}\text { Incomplete outcome data } \\
\text { (attrition bias) }\end{array}$ & & & \\
\hline Selective outcome reporting? & & & \\
\hline (reporting bias) & & & \\
\hline Other bias & & & \\
\hline Notes: & & \\
\hline
\end{tabular}

Participants

\begin{tabular}{|l|l|l|}
\hline & Description as stated in report/paper & $\begin{array}{l}\text { Location in text } \\
\text { (pg \&/fig/table) }\end{array}$ \\
\hline Population size & & \\
\hline Baseline imbalances & & \\
\hline Withdrawals and exclusions & & \\
\hline
\end{tabular}




\begin{tabular}{|l|l|l|}
\hline & Description as stated in report/paper & $\begin{array}{l}\text { Location in text } \\
\text { (pg \&/fig/table) }\end{array}$ \\
\hline Median age in years & & \\
\hline Sex & & \\
\hline Race/Ethnicity & & \\
\hline First-line drug regimen details & & \\
\hline Population HIV prevalence & & \\
\hline $\begin{array}{l}\text { Other relevant socio- } \\
\text { demographics }\end{array}$ & & \\
\hline Subgroups measured & & \\
\hline Subgroups reported & & \\
\hline
\end{tabular}

Intervention groups

Intervention Group 1

\begin{tabular}{|l|l|l|}
\hline & Description as stated in report/paper & $\begin{array}{l}\text { Location in text } \\
\text { (pg \&/fig/table })\end{array}$ \\
\hline Group name & & \\
\hline Group size & & \\
\hline Duration of monitoring period & & \\
\hline
\end{tabular}




\begin{tabular}{|l|l|l|}
\hline & Description as stated in report/paper & $\begin{array}{l}\text { Location in text } \\
\text { (pg \& /fig/table) }\end{array}$ \\
\hline Timing \\
(frequency of monitoring)
\end{tabular}

Intervention Group 2

\begin{tabular}{|l|l|l|}
\hline & Description as stated in report/paper & $\begin{array}{l}\text { Location in text } \\
\text { (pg \& /fig/table) }\end{array}$ \\
\hline Group name & & \\
\hline Group size & & \\
\hline Duration of monitoring period & & \\
\hline (fiming & & \\
\hline Co-interventions & & \\
\hline Notes: & & \\
\hline
\end{tabular}


Outcome 1

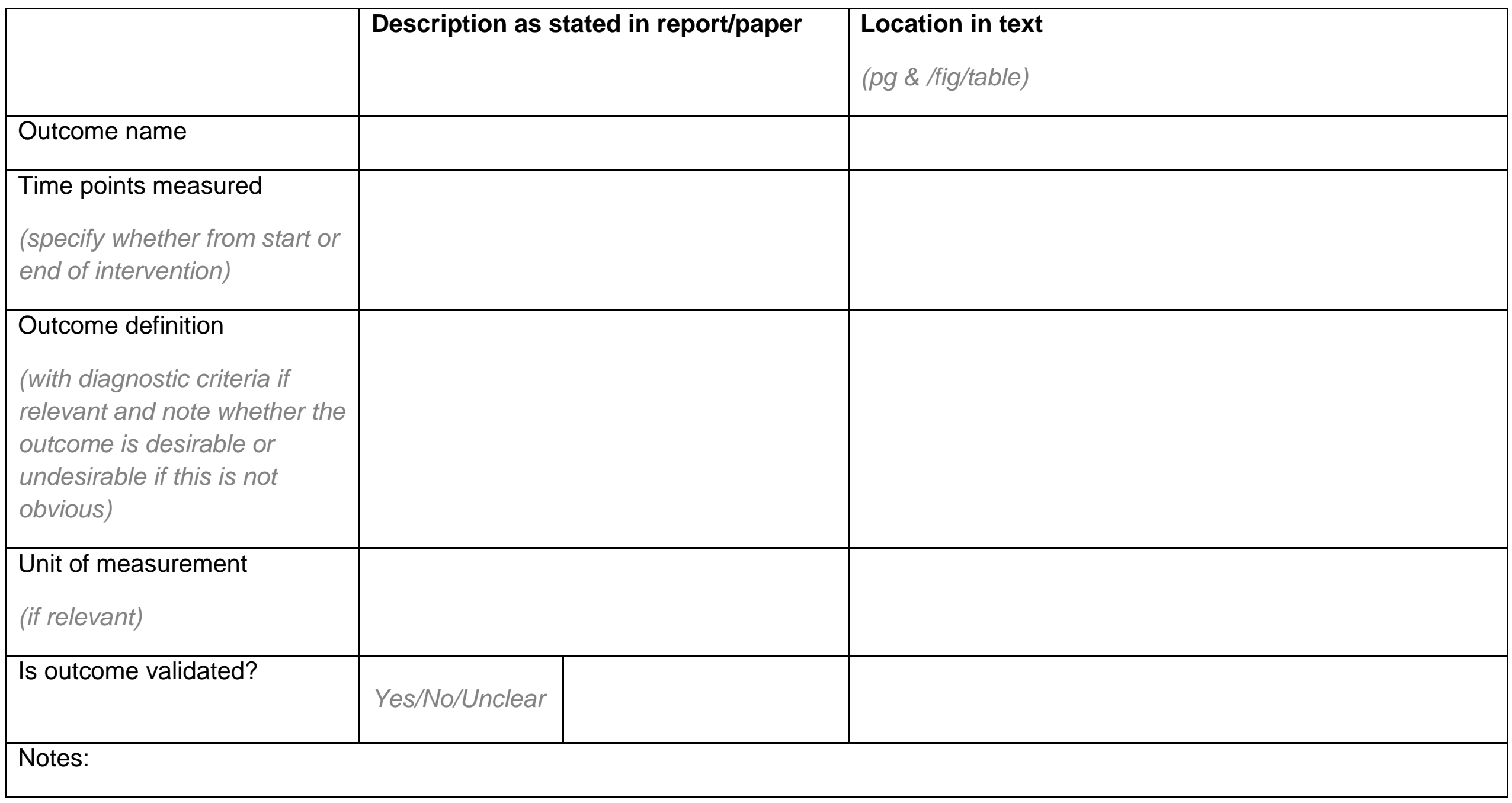


For randomised or non-randomised study - Dichotomous outcome

\begin{tabular}{|c|c|c|c|c|c|}
\hline & \multicolumn{4}{|c|}{ Description as stated in report/paper } & $\begin{array}{l}\text { Location in text } \\
(p g \& / f i g / t a b l e)\end{array}$ \\
\hline \multicolumn{6}{|l|}{ Outcome } \\
\hline \multicolumn{6}{|c|}{$\begin{array}{l}\text { Time point } \\
\text { (specify whether from start or } \\
\text { end of intervention) }\end{array}$} \\
\hline \multirow[t]{2}{*}{ Results } & \multicolumn{2}{|c|}{$\geq 3$ VLs per year } & \multicolumn{2}{|c|}{$\leq 2$ VLs per year } & \\
\hline & No. events & No. participants & No. events & No. participants & \\
\hline \multirow[t]{3}{*}{ Baseline data } & \multicolumn{2}{|c|}{$\geq 3$ VLs per year } & \multicolumn{2}{|c|}{$\leq 2$ VLs per year } & \\
\hline & No. events & No. participants & No. events & No. participants & \\
\hline & & & & & \\
\hline
\end{tabular}




\begin{tabular}{|c|c|c|}
\hline & Description as stated in report/paper & $\begin{array}{l}\text { Location in text } \\
(p g \& / f i g / t a b l e)\end{array}$ \\
\hline $\begin{array}{l}\text { Effect sizes (Cohen's d, odds } \\
\text { ratio, risk ratio } \\
\text { Or data allowing to estimate } \\
\text { effect sizes } \\
\text {-e.g. mean + SD + } n \text { in each } \\
\text { group, results of a statistical } \\
\text { test) }\end{array}$ & & \\
\hline
\end{tabular}

For randomised or non-randomised study - Continuous outcome

\begin{tabular}{|l|l|l|l|}
\hline & \multicolumn{1}{|l|}{ Description as stated in report/paper } & $\begin{array}{l}\text { Location in } \\
\text { text } \\
\text { (pg \&/fig/table) }\end{array}$ \\
\hline Outcome & & \\
\hline Time point & & \\
\hline $\begin{array}{l}\text { Post-intervention or change } \\
\text { from baseline? }\end{array}$ & & $\mathbf{2}$ VLs per year & \\
\hline Results & $\mathbf{2}$ VLs per year & \\
\hline
\end{tabular}




\begin{tabular}{|c|c|c|c|c|c|c|c|}
\hline & \multicolumn{6}{|c|}{ Description as stated in report/paper } & \multirow{2}{*}{$\begin{array}{l}\text { Location in } \\
\text { text } \\
(\mathrm{pg} \& / \mathrm{fig} / \mathrm{tab} / \mathrm{e})\end{array}$} \\
\hline & Mean & $\begin{array}{l}\text { SD (or } \\
\text { other } \\
\text { variance) }\end{array}$ & $\begin{array}{l}\text { No. } \\
\text { participants }\end{array}$ & Mean & $\begin{array}{l}\text { SD (or other } \\
\text { variance) }\end{array}$ & No. participants & \\
\hline \multirow[t]{2}{*}{ Baseline data } & \multicolumn{3}{|c|}{$\geq 3$ VLs per year } & \multicolumn{3}{|c|}{$\leq 2$ VLs per year } & \\
\hline & Mean & $\begin{array}{l}\text { SD (or } \\
\text { other } \\
\text { variance) }\end{array}$ & $\begin{array}{l}\text { No. } \\
\text { participants }\end{array}$ & Mean & $\begin{array}{l}\text { SD (or other } \\
\text { variance) }\end{array}$ & No. participants & \\
\hline \multicolumn{8}{|l|}{$\begin{array}{l}\text { Effect sizes (Cohen's d, odds } \\
\text { ratio, risk ratio Or data } \\
\text { allowing to estimate effect } \\
\text { sizes -e.g. mean }+S D+n \text { in } \\
\text { each group, results of a } \\
\text { statistical test) }\end{array}$} \\
\hline Notes: & & & & & & & \\
\hline
\end{tabular}

For randomised or non-randomised study - Other outcome 


\begin{tabular}{|c|c|c|c|c|c|}
\hline & \multicolumn{4}{|c|}{ Description as stated in report/paper } & Location in text \\
\hline \multicolumn{6}{|l|}{ Outcome } \\
\hline \multicolumn{6}{|l|}{ Type of outcome } \\
\hline \multirow[t]{2}{*}{ Results } & $\begin{array}{l}\mathbf{2 3} \text { VLs per year } \\
\text { result }\end{array}$ & $\begin{array}{l}\text { SD (or other } \\
\text { variance) }\end{array}$ & $\leq 2$ VLs per year & $\begin{array}{l}\text { SD (or } \\
\text { other } \\
\text { variance) }\end{array}$ & \\
\hline & \multicolumn{2}{|l|}{ Overall results } & \multicolumn{2}{|c|}{ SE (or other variance) } & \\
\hline No. participant & \multicolumn{2}{|l|}{$\geq 3$ VLs per year } & \multicolumn{2}{|l|}{$\leq 2$ VLs per year } & \\
\hline \multicolumn{6}{|l|}{$\begin{array}{l}\text { Effect sizes (Cohen's d, odds } \\
\text { ratio, risk ratio Or data } \\
\text { allowing to estimate effect } \\
\text { sizes -e.g. mean }+S D+n \text { in } \\
\text { each group, results of a } \\
\text { statistical test) }\end{array}$} \\
\hline Notes: & & & & & \\
\hline
\end{tabular}


Applicability

\begin{tabular}{|l|l|l|}
\hline $\begin{array}{l}\text { Have important populations been excluded from } \\
\text { the study? }\end{array}$ & Yes/No/Unclear \\
$\begin{array}{l}\text { (consider disadvantaged populations, and } \\
\text { possible differences in the intervention effect) }\end{array}$ & & \\
\hline $\begin{array}{l}\text { Is the intervention likely to be aimed at } \\
\text { disadvantaged groups? } \\
\text { (e.g. lower socioeconomic groups) }\end{array}$ & Yes/No/Unclear & \\
\hline $\begin{array}{l}\text { Does the study directly address the review } \\
\text { question? } \\
\text { (any issues of partial or indirect applicability) }\end{array}$ & Yes/No/Unclear & \\
\hline Notes: & \\
\hline
\end{tabular}

Other information

\begin{tabular}{|l|l|l|}
\hline & $\begin{array}{l}\text { Description as stated } \\
\text { in report/paper }\end{array}$ & $\begin{array}{l}\text { Location in text } \\
\text { (pg \& /fig/table) }\end{array}$ \\
\hline Key conclusions of study authors & & \\
\hline limitations & & \\
\hline Generalisability & & \\
\hline Further study information requested & & \\
\hline
\end{tabular}


ANNEXURE D:

CHARACTERISTICS OF STUDIES 


\section{CHARACTERISTICS OF INCLUDED STUDIES}

\begin{tabular}{|l|l|}
\hline Bryant. 2012 & Cohort Study with Kaplan-Meier Survival analysis \\
\hline Methods & $\begin{array}{l}\text { ARV naive, HIV-1-infected patients treated with zidovudine (ZDV), lamivudine (3TC), and efavirenz } \\
\text { (EFV). }\end{array}$ \\
\hline Participants & $\begin{array}{l}\text { Viral load at baseline and every 6 months versus reduced viral load monitoring with CD4 count at } \\
\text { baseline and viral load testing at 6, 36, and 60 months }\end{array}$ \\
\hline Interventions & Median time for the detection of virologic failure \\
\hline Outcomes
\end{tabular}

\begin{tabular}{|l|l|l|}
\hline Risk of bias table: Bryant. 2012 & Authors' judgement & Support for judgement \\
\hline Bias & Unclear risk & N/A, see Table 1. \\
\hline Random sequence generation (selection bias) & N/A, see Table 1. \\
\hline Allocation concealment (selection bias) & Unclear risk & N/A, see Table 1. \\
\hline Blinding of participants and personnel (performance bias) & Unclear risk & N/A, see Table 1. \\
\hline Blinding of outcome assessment (detection bias) & Unclear risk & Nee Table 1. \\
\hline Incomplete outcome data (attrition bias) & Unclear risk & N/A, see Table 1. \\
\hline Selective reporting (reporting bias) & Unclear risk & N/A, see Table 1. \\
\hline Other bias & Unclear risk & \\
\hline
\end{tabular}




\begin{tabular}{|c|c|}
\hline \multicolumn{2}{|l|}{ Caniglia. 2016} \\
\hline Methods & Cohort Study with a Parallel design \\
\hline Participants & $\begin{array}{l}\text { Antiretroviral-naive individuals who initiated ART and became virologically suppressed within } 12 \\
\text { months were followed from the date of suppression. }\end{array}$ \\
\hline Interventions & HIV-RNA monitoring strategies: once every (3 \pm 1 months);(6 \pm 1 months);(9-12 \pm 1 months) \\
\hline Outcomes & virologic failure \\
\hline
\end{tabular}

\begin{tabular}{|l|l|l|}
\hline Risk of bias table: Caniglia. 2016 & Support for judgement \\
\hline Bias & Authors' judgement & N/A, see Table 1. \\
\hline Random sequence generation (selection bias) & Unclear risk & N/A, see Table 1. \\
\hline Allocation concealment (selection bias) & Unclear risk & N/A, see Table 1. \\
\hline Blinding of participants and personnel (performance bias) & Unclear risk & N/A, see Table 1. \\
\hline Blinding of outcome assessment (detection bias) & Unclear risk & N/A, see Table 1. \\
\hline Incomplete outcome data (attrition bias) & Unclear risk & N/A, see Table 1. \\
\hline Selective reporting (reporting bias) & Unclear risk & N/A, see Table 1. \\
\hline Other bias & Unclear risk & \\
\hline
\end{tabular}

\begin{tabular}{|l|l|}
\hline Chaiwarith. 2011 & Retrospective Observational Cohort Study \\
\hline Methods & HIV-infected patients on a stable regimen \\
\hline Participants & frequency of monitoring of the stable patients \\
\hline Interventions & virological failure and number of reverse transcriptase (RT) mutations \\
\hline Outcomes & Abstract only \\
\hline Notes &
\end{tabular}

\begin{tabular}{|l|l|l|}
\hline Risk of bias table: Chaiwarith. 2011 & Authors' judgement & Support for judgement \\
\hline Bias & Unclear risk & N/A, see Table 1. \\
\hline Random sequence generation (selection bias) & N/A, see Table 1. \\
\hline Allocation concealment (selection bias) & Unclear risk & N/A, see Table 1. \\
\hline Blinding of participants and personnel (performance bias) & N/A, see Table 1. & N/A, see Table 1. \\
\hline Blinding of outcome assessment (detection bias) & Unclear risk & N/A, see Table 1. \\
\hline Incomplete outcome data (attrition bias) & Unclear risk & N/A, see Table 1. \\
\hline Selective reporting (reporting bias) & Unclear risk & Unclear risk \\
\hline Other bias & & \\
\hline
\end{tabular}




\begin{tabular}{|l|l|}
\hline Reekie. 2008 & Prospective cohort study \\
\hline Methods & $\begin{array}{l}\text { All included patients from EuroSIDA were on a stable and fully suppressed cART regimen for a } \\
\text { period of 1 year }\end{array}$ \\
\hline Participants & frequency of monitoring of the stable patients \\
\hline Interventions & Risk of treatment failure \\
\hline Outcomes &
\end{tabular}

\section{Risk of bias table: Reekie. 2008}

\section{Bias}

Random sequence generation (selection bias)

Allocation concealment (selection bias)

Blinding of participants and personnel (performance bias)

Blinding of outcome assessment (detection bias)

Incomplete outcome data (attrition bias)

Selective reporting (reporting bias)

Other bias

\section{Authors' judgement}

Unclear risk

Unclear risk

Unclear risk

Unclear risk

Unclear risk

Unclear risk

Unclear risk

\section{Support for judgement}

N/A, see Table 1.

N/A, see Table 1.

N/A, see Table 1.

N/A, see Table 1.

N/A, see Table 1.

N/A, see Table 1.

N/A, see Table 1.

\begin{tabular}{|c|c|}
\hline \multicolumn{2}{|l|}{ Romih. 2010} \\
\hline Methods & retrospective cohort study \\
\hline Participants & $\begin{array}{l}\text { ART naive patients who were initially well suppressed and considered fully adherent during the first } \\
15 \text { months of CART }\end{array}$ \\
\hline Interventions & different viral load monitoring frequencies \\
\hline Outcomes & CART failure \\
\hline
\end{tabular}

\begin{tabular}{|l|l|l|}
\hline Risk of bias table: Romih. 2010 & Authors' judgement & Support for judgement \\
\hline Bias & Unclear risk & N/A, see Table 1. \\
\hline Random sequence generation (selection bias) & N/A, see Table 1. \\
\hline Allocation concealment (selection bias) & Unclear risk & N/A, see Table 1. \\
\hline Blinding of participants and personnel (performance bias) & Unclear risk & N/A, see Table 1. \\
\hline Blinding of outcome assessment (detection bias) & Unclear risk & N/A, see Table 1. \\
\hline Incomplete outcome data (attrition bias) & Unclear risk & N/A, see Table 1. \\
\hline Selective reporting (reporting bias) & Unclear risk & N/A, see Table 1. \\
\hline Other bias & Unclear risk & \\
\hline
\end{tabular}




\begin{tabular}{|l|l|}
\hline Schneider. 2011 & Cohort study \\
\hline Methods & 304 ARV naive, HIV-1-infected patients \\
\hline Participants & different viral load monitoring frequencies \\
\hline Interventions & costs and clinical outcomes \\
\hline Outcomes &
\end{tabular}

\begin{tabular}{|l|l|l|}
\hline Risk of bias table: Schneider. 2011 & Authors' judgement & Support for judgement \\
\hline Bias & Unclear risk & N/A, see Table 1. \\
\hline Random sequence generation (selection bias) & N/A, see Table 1. \\
\hline Allocation concealment (selection bias) & Unclear risk & N/A, see Table 1. \\
\hline Blinding of participants and personnel (performance bias) & Unclear risk & N/A, see Table 1. \\
\hline Blinding of outcome assessment (detection bias) & Unclear risk & N/A, see Table 1. \\
\hline Incomplete outcome data (attrition bias) & Unclear risk & N/A, see Table 1. \\
\hline Selective reporting (reporting bias) & Unclear risk & N/A, see Table 1. \\
\hline Other bias & Unclear risk & \\
\hline
\end{tabular}

\begin{tabular}{|l|l|}
\hline Young. 2015 & Observational Cohort Study \\
\hline Methods & $\begin{array}{l}\text { Antiretroviral-naive individuals who initiated ART and became virologically suppressed within 12 } \\
\text { months were followed from the date of suppression. }\end{array}$ \\
\hline Participants & frequency of VL testing \\
\hline Interventions & $\begin{array}{l}\text { virologic failure (VF), defined as at least 1 VL } \geq 200 \text { copies/mL during the 2-year followup period after } \\
\text { the index date }\end{array}$ \\
\hline Outcomes
\end{tabular}

\begin{tabular}{|l|l|l|}
\hline Risk of bias table: Young. 2015 & Authors' judgement & Support for judgement \\
\hline Bias & Unclear risk & N/A, see Table 1. \\
\hline Random sequence generation (selection bias) & N/A, see Table 1. \\
\hline Allocation concealment (selection bias) & Unclear risk & N/A, see Table 1. \\
\hline Blinding of participants and personnel (performance bias) & Unclear risk & N/A, see Table 1. \\
\hline Blinding of outcome assessment (detection bias) & Unclear risk & N/A, see Table 1. \\
\hline Incomplete outcome data (attrition bias) & Unclear risk & N/A, see Table 1. \\
\hline Selective reporting (reporting bias) & Unclear risk & N/A, see Table 1. \\
\hline Other bias & Unclear risk & \\
\hline
\end{tabular}




\begin{tabular}{|l|l|}
\hline Weissman. 2016 & Randomized controlled trial(RCT) \\
\hline Methods & HIV positive patients who are on cART and on PI based regimen and on a non-nucleoside regimen \\
\hline Participants & frequency of monitoring of the stable patients \\
\hline Interventions & VL failure, quality of life, and adherence \\
\hline Outcomes &
\end{tabular}

\begin{tabular}{|l|l|l|}
\hline Risk of bias table: Weissman. 2016 & Authors' judgement & Support for judgement \\
\hline Bias & Low risk & $\begin{array}{l}\text { Patients were randomized to every 4 months } \\
\text { monitoring (Group I) or 6 month monitoring } \\
\text { (Group II). Baseline characteristics did not } \\
\text { differ between the groups. }\end{array}$ \\
\hline Allocation concealment (selection bias) & $\begin{array}{l}\text { Standard care included: medical provider visits } \\
\text { and laboratory monitoring, which included CD4 } \\
\text { county and VL among others. }\end{array}$ & Not reported. \\
\hline Blinding of participants and personnel (performance bias) & Now risk & Not reported. \\
\hline Blinding of outcome assessment (detection bias) & Unclear risk & $\begin{array}{l}\text { The primary outcome was the same as in the } \\
\text { one reported }\end{array}$ \\
\hline Incomplete outcome data (attrition bias) & Unclear risk & Unclear risk \\
\hline Selective reporting (reporting bias) & Low risk & Low risk \\
\hline Other bias & & \\
\hline
\end{tabular}




\section{Characteristics of excluded studies}

\begin{tabular}{|l|l|}
\hline Braithwaite. 2014 & $\begin{array}{l}\text { Study did not look at treatment outcomes such as virologic failure, switch rates to second-line ART, adherence, } \\
\text { and drug resistance measurements }\end{array}$ \\
\hline Reason for exclusion &
\end{tabular}

\begin{tabular}{|l|l|}
\hline Haubrich. 2001 & \\
\hline Reason for exclusion & $\begin{array}{l}\text { Study did not require individuals to be virologically suppressed at entry and did not look at treatment outcomes } \\
\text { such as virologic failure, switch rates to second-line ART, adherence, and drug resistance measurements }\end{array}$ \\
\hline
\end{tabular}

\begin{tabular}{|l|l|}
\hline Raboud. 2010 & $\begin{array}{l}\text { The outcome of interest is the frequency of } V L \text { monitoring, instead of clinical/health outcomes due to variations } \\
\text { in frequency of } V L \text { testing }\end{array}$ \\
\hline Reason for exclusion &
\end{tabular}

Rossouw. 2017

\begin{tabular}{|l|l|}
\hline Reason for exclusion & All patients had failed a first line NNRTI-based HAART regimen \\
\hline
\end{tabular}

\begin{tabular}{|l|l|}
\hline Thirunavukarasu. 2016 & $\begin{array}{l}\text { Study does not evaluate the frequency of viral load monitoring after initiation of ART, instead it evaluates the } \\
\text { frequency and patterns of HIV-1 drug-resistance mutations }\end{array}$ \\
\hline Reason for exclusion & frealu
\end{tabular}


ANNEXURE E

SEARCH STRATEGIES AND RESULTS 
Table 1: Summary of Databases Searched

\begin{tabular}{|c|c|c|c|c|c|}
\hline $\begin{array}{l}\text { Tabl } \\
\text { e }\end{array}$ & $\begin{array}{l}\text { Vendorl } \\
\text { Interface }\end{array}$ & Database & $\begin{array}{l}\text { Date } \\
\text { searched }\end{array}$ & $\begin{array}{l}\text { Database } \\
\text { update }\end{array}$ & Searcher(s) \\
\hline $1 a$ & $\begin{array}{l}\text { National } \\
\text { Library of } \\
\text { Medicine }\end{array}$ & $\begin{array}{l}\text { Multiple } \\
\text { Database }\end{array}$ & $6 / 17 / 2017$ & $6 / 17 / 2017$ & $\begin{array}{l}50778587 \text { ZHOU } \\
\text { TOLYBERT }\end{array}$ \\
\hline $1 b$ & $\begin{array}{l}\text { EBSCOho } \\
\text { st } \\
\text { Research } \\
\text { Databases }\end{array}$ & $\begin{array}{l}\text { Multiple } \\
\text { Database }\end{array}$ & $6 / 24 / 2017$ & $6 / 24 / 2017$ & $\begin{array}{l}50778587 \text { ZHOU } \\
\text { TOLYBERT }\end{array}$ \\
\hline $1 c$ & Ovid & $\begin{array}{l}\text { Multiple } \\
\text { Database }\end{array}$ & $6 / 24 / 2017$ & $6 / 23 / 2017$ & $\begin{array}{l}50778587 \text { ZHOU } \\
\text { TOLYBERT }\end{array}$ \\
\hline $1 d$ & Informit & $\begin{array}{l}\text { multiple } \\
\text { databases }\end{array}$ & $7 / 3 / 2017$ & $7 / 3 / 2017$ & $\begin{array}{l}50778587 \text { ZHOU } \\
\text { TOLYBERT }\end{array}$ \\
\hline $1 e$ & Proquest & $\begin{array}{l}\text { multiple } \\
\text { databases }\end{array}$ & $7 / 3 / 2017$ & $7 / 3 / 2017$ & $\begin{array}{l}50778587 \text { ZHOU } \\
\text { TOLYBERT }\end{array}$ \\
\hline $1 f$ & $\begin{array}{l}\text { WEB OF } \\
\text { SCIENCE }\end{array}$ & $\begin{array}{l}\text { multiple } \\
\text { databases }\end{array}$ & $7 / 3 / 2017$ & $7 / 3 / 2017$ & $\begin{array}{l}50778587 \text { ZHOU } \\
\text { TOLYBERT }\end{array}$ \\
\hline
\end{tabular}


Table 1a National Library of Medicine search strategy

Provider/Interface National Library of Medicine

\section{Database PubMed}

Date searched June 17, 2017

Database update June 17, 2017

Search developer(s) $\quad 50778587$ ZHOU TOLYBERT

Limit to English Yes

Date Range Publication date from 1996/01/01

\begin{tabular}{|c|c|}
\hline \#1 & $\begin{array}{l}\text { Search (((HIV-1*) OR human immunodeficiency virus*)))) AND ((((HIV Viral } \\
\text { Load Monitoring Frequency[Title/Abstract]) OR frequency of plasma HIV-1 } \\
\text { RNA monitoring[Title/Abstract]) OR rates of HIV-1 viral load } \\
\text { monitoring[Title/Abstract]) OR Frequency of HIV-1 viral load } \\
\text { monitoring[Title/Abstract]) OR human immunodeficiency virus RNA } \\
\text { measurement[Title/Abstract]) OR frequent routine monitoring[Title/Abstract]) } \\
\text { OR Frequency Virological monitoring[Title/Abstract]))) Filters: Publication date } \\
\text { from 1996/01/01 }\end{array}$ \\
\hline
\end{tabular}


Table 1b: EBSCOhost Research Databases

\begin{tabular}{|c|c|}
\hline Provider/Interface & $\begin{array}{l}\text { EBSCOhost Research } \\
\text { Databases }\end{array}$ \\
\hline Database & Multiple Databases \\
\hline searched & $6 / 24 / 2017$ \\
\hline Database update & $6 / 24 / 2017$ \\
\hline $\begin{array}{l}\text { Search } \\
\text { developer(s) }\end{array}$ & $50778587 \mathrm{ZHOL}$ \\
\hline Limit to English & Yes \\
\hline Date Range & $\begin{array}{l}\text { Publication date from } \\
1996 / 01 / 01\end{array}$ \\
\hline rov & $\begin{array}{l}\text { EBSCOhost Research } \\
\text { Databases }\end{array}$ \\
\hline
\end{tabular}

\begin{tabular}{|l|l|}
\hline S1 & $\begin{array}{l}\text { TX HIV Viral Load Monitoring Frequency OR TX frequency of plasma HIV-1 } \\
\text { RNA monitoring OR TX rates of HIV-1 viral load monitoring OR TX Frequency } \\
\text { of HIV-1 viral load monitoring OR TX human immunodeficiency virus RNA } \\
\text { measurement OR TX frequent routine monitoring OR TX Frequency Virological } \\
\text { monitoring }\end{array}$ \\
\hline & Limiters - Publication Date: 19960101-20171231; Hidden NetLibrary Holdings \\
\hline & Narrow by Subject: - diagnosis \\
\hline & Narrow by Subject: - viraemia \\
\hline Narrow by Subject: - plasma (blood) & Narrow by Subject: - blood plasma \\
\hline & Narrow by Subject: - aids \\
\hline Narrow by Subject: - acquired immune deficiency syndrome \\
\hline Narrow by Subject: - human immunodeficiency virus \\
\hline Narrow by Subject: - antiretroviral agents \\
\hline Narrow by Subject: - hiv-1 infections \\
\hline
\end{tabular}




\begin{tabular}{|c|}
\hline Narrow by Subject: - antiviral agents \\
\hline Narrow by Subject: - human immunodeficiency virus infections \\
\hline Narrow by Subject: - hiv infections \\
\hline Narrow by Subject: - viral load \\
\hline Narrow by Subject: - human immunodeficiency virus 1 \\
\hline Narrow by SubjectMajor: - drug resistance \\
\hline Narrow by SubjectMajor: - treatment failure \\
\hline Narrow by SubjectMajor: - monitoring \\
\hline Narrow by SubjectMajor: - diagnosis \\
\hline Narrow by SubjectMajor: - viraemia \\
\hline Narrow by SubjectMajor: - regimens \\
\hline Narrow by SubjectMajor: - blood plasma \\
\hline Narrow by SubjectMajor: - acquired immune deficiency syndrome \\
\hline Narrow by SubjectMajor: - antiretroviral agents \\
\hline Narrow by SubjectMajor: - drug therapy \\
\hline Narrow by SubjectMajor: - rna \\
\hline Narrow by SubjectMajor: - hiv-1 infections \\
\hline Narrow by SubjectMajor: - antiviral agents \\
\hline Narrow by SubjectMajor: - hiv infections \\
\hline Narrow by SubjectMajor: - human immunodeficiency viruses \\
\hline Narrow by SubjectMajor: - viral load \\
\hline Narrow by SubjectMajor: - human immunodeficiency virus 1 \\
\hline Narrow by SubjectThesaurus: - azt (drug) \\
\hline Narrow by SubjectThesaurus: - viremia \\
\hline Narrow by SubjectThesaurus: - diagnosis \\
\hline Narrow by SubjectThesaurus: - virology \\
\hline Narrow by SubjectThesaurus: - blood plasma \\
\hline
\end{tabular}




\begin{tabular}{|l|l|}
\hline & Narrow by SubjectThesaurus: - aids (disease) \\
\hline & Narrow by SubjectThesaurus: - drug therapy \\
\hline & Narrow by SubjectThesaurus: - highly active antiretroviral therapy \\
\hline & Narrow by SubjectThesaurus: - hiv (viruses) \\
\hline & Narrow by SubjectThesaurus: - viral load \\
\hline & Narrow by SubjectThesaurus: - rna \\
\hline & Narrow by SubjectThesaurus: - antiviral agents \\
\hline & Narrow by SubjectThesaurus: - antiretroviral agents \\
\hline
\end{tabular}


Table 1c: Ovid search strategy

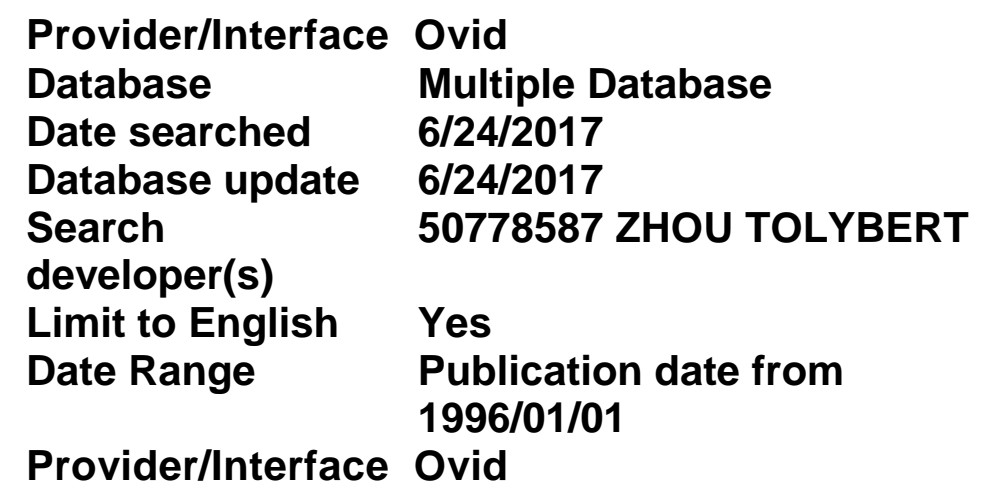

\begin{tabular}{|l|l|}
\hline$\# 1$ & (HIV-1 or human immunodeficiency virus).af. \\
\hline$\# 2$ & $\begin{array}{l}\text { (HIV Viral Load Monitoring Frequency or frequency of plasma HIV-1 RNA } \\
\text { monitoring or rates of HIV-1 viral load monitoring or human immunodeficiency } \\
\text { virus RNA measurement Frequency of HIV-1 viral load monitoring or frequent } \\
\text { routine monitoring or Frequency Virological monitoring).af. }\end{array}$ \\
\hline$\# 3$ & 1 AND 2 \\
\hline
\end{tabular}


Table 1d: Informit search strategy

$\begin{array}{ll}\text { Provider/Interface } & \text { informit } \\ \text { Database } & \text { multiple databases } \\ \text { Date searched } & 7 / 3 / 2017 \\ \text { Database update } & 7 / 3 / 2017 \\ \text { Search } & 50778587 \text { ZHOU TOLYBERT } \\ \text { developer(s) } & \\ \text { Limit to English } & \text { Yes } \\ \text { Date Range } & \begin{array}{l}\text { Publication date from } \\ 1996 / 01 / 01\end{array} \\ \text { Provider/Interface } & \text { informit }\end{array}$

\begin{tabular}{|l|l|}
\hline & (ALLTERMS,FC:frequency ALLTERMS,FC:of ALLTERMS,FC:plasma \\
& ALLTERMS,FC:HIV-1 ALLTERMS,FC:RNA ALLTERMS,FC:monitoring) OR \\
& (ALLTERMS,FC:HIV ALLTERMS,FC:Viral ALLTERMS,FC:Load \\
& ALLTERMS,FC:Monitoring ALLTERMS,FC:Frequency) OR \\
& (ALLTERMS,FC:rates ALLTERMS,FC:of ALLTERMS,FC:HIV-1 \\
& ALLTERMS,FC:viral ALLTERMS,FC:load ALLTERMS,FC:monitoring) AND \\
(ALLTERMS,FC:HIV-1 OR ALLTERMS,FC:human \\
ALLTERMS,FC:immunodeficiency ALLTERMS,FC:virus)
\end{tabular} 
Table 1e: Proquest search strategy

\author{
Provider/Interface Proquest \\ Database \\ multiple databases \\ Date searched 7/3/2017 \\ Database update $\quad 7 / 3 / 2017$ \\ Search \\ 50778587 ZHOU TOLYBERT \\ developer(s) \\ Limit to English \\ Date Range \\ Yes \\ Publication date from \\ 1996/01/01 \\ Provider/Interface Proquest
}

\begin{tabular}{|l|l|}
\hline$\# 1$ & $\begin{array}{l}\text { ab(HIV Viral Load Monitoring Frequency) OR ab(frequency of plasma HIV-1 } \\
\text { RNA monitoring) OR ab(rates of HIV-1 viral load monitoring) OR ab(Frequency } \\
\text { of HIV-1 viral load monitoring) OR ab(human immunodeficiency virus RNA } \\
\text { measurement) OR ab(frequent routine monitoring) OR ab(Frequency } \\
\text { Virological monitoring) }\end{array}$ \\
\hline
\end{tabular}


Table 1f: WEB OF SCIENCE search strategy

\section{Provider/Interface WEB OF SCIENCE \\ Database multiple databases \\ Date searched 7/3/2017 \\ Database update $7 / 3 / 2017$ \\ Search \\ 50778587 ZHOU TOLYBERT \\ developer(s) \\ Limit to English \\ Date Range \\ Yes \\ Publication date from \\ 1996/01/01 \\ Provider/Interface WEB OF SCIENCE}

\begin{tabular}{|l|l|}
\hline TITLE: (frequency of plasma HIV-1 RNA monitoring) OR TITLE: (Frequency of \\
Virological monitoring) OR TITLE: (frequent routine \\
monitoring) ORTITLE: (human immunodeficiency virus RNA \\
measurement) OR TITLE: (Frequency of HIV-1 viral load \\
monitoring) OR TITLE: (rates of HIV-1 viral load monitoring) OR TITLE: (HIV \\
Viral Load Monitoring Frequency) ANDTOPIC: (HIV-1)
\end{tabular}


Table 1g: Other sources search strategy table

\begin{tabular}{|l|l|l|}
\hline \multicolumn{2}{|l|}{ Data Source } & Results \\
\hline Vendorl Interface & Database & New \\
\hline Author Search & n/a & 0 \\
\hline bibliographies & bibliographies & 4 \\
\hline $\begin{array}{l}\text { Handsearching } \\
\text { Conflor }\end{array}$ & $\begin{array}{l}\text { handsearching journals } \\
\text { \& conference } \\
\text { proceedings }\end{array}$ & 0 \\
\hline Google & Google Scholar & 0 \\
\hline Total & & 4 \\
\hline
\end{tabular}

\section{Bibliographies searched}

CANIGLIA, E.C.S.D., SABIN, C., ROBINS, J.M., LOGAN, R., CAIN, L.E., ABGRALL, S., MUGAVERO, M.J., HERNANDEZDIAZ, S.D.H., MEYER, L., SENG, R., DROZD, D.R., SEAGE, G.R.I.I.I., BONNET, F., DABIS, F., MOORE, R.R., REISS, P., VAN SIGHEM, A., MATHEWS, W.C., DEL AMO, J., MORENO, S., DEEKS, S.G., MUGA, R., BOSWELL, S.L., FERRER, E., ERON, J.J., NAPRAVNIK, S., JOSE, S., PHILLIPS, A., OLSON, A., JUSTICE, A.C., TATE, J.P., BUCHER, H.C., EGGER, M., TOULOUMI, G., STERNE, J.A., COSTAGLIOLA, D., SAAG, M., HERNAN, M.A.D.H. and ON BEHALF OF THE CENTER FOR AIDS RESEARCH NETWORK OF INTEGRATED CLINICAL SYSTEMS AND THE HIVCAUSAL COLLABORATION, 2016. When to Monitor CD4 Cell Count and HIV RNA to Reduce Mortality and AIDS-Defining Illness in Virologically Suppressed HIVPositive Persons on Antiretroviral Therapy in High-Income Countries: A Prospective Observational Study. JAIDS Journal of Acquired Immune Deficiency Syndromes, 72(2), pp. 214-221.

ROMIH, V., ZIDOVEC LEPEJ, S., GEDIKE, K., LUKAS, D. and BEGOVAC, J., 2010. Frequency of HIV-1 viral load monitoring of patients initially successfully treated with combination antiretroviral therapy. PloS one, 5(11), pp. e15051. 